ISSN (print) 0867-2008 / ISSN (online) 2391-75 I2

DOI: http://dx.doi.org/10.12775/OM.2019.006

\title{
ThOMAS KRÄMER*
}

Frechen

Germany

thomas_kraemer@yahoo.com

\section{EXEMT, ABER NICHT AUTARK - ZUM VERHÄLTNIS DER SÜDFRANZÖSISCHEN JOHANNITER UND TEMPLER ZU DEN KIRCHLICHEN STRUKTUREN DES MIDI}

\section{KEYWORDS}

the Middle Ages; military orders; Hospitallers of St. John; Templar Order; France; clergy; cooperation; conflicts

\section{ABstract \\ Exempt, but not autarkical - On the relationship between the Hospitallers of St. John and the Templars to the ecclesiastical structures in the Midi}

The contribution explores the complex relationship between the Hospitallers of St. John respectively the Templars and the clergy in Southern France by means of two case studies: the possession of chapels and churches by these military orders and their exemption. Initially, promotion of the episcopacy and cooperation between both sides were the predominant characteristics. Without the support of the bishops, the spread of the military orders in the Midi would not have been possible. After this period, the relationship deteriorated significantly. This change was especially disadvantageous for the military orders. In spite of the far reaching protection granted by the exemption from episcopal interference, both orders remained dependent on the regional clergy. This particularly became obvious in the fields of the protection and the enforcement of the orders' rights and interests. Important provisions of the canon law reinforced in several ways the dependency on the episcopal jurisdiction.

* ORCID: https://orcid.org/0000-000 I-5404-649 I 


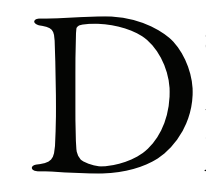
as Verhältnis der Ritterorden zu den kirchlichen Strukturen Südfrankreichs war vom Beginn des I 2 . bis zu den ersten Jahrzehnten des I 4. Jahrhunderts außerordentlich vielschichtig und blieb während des gesamten Zeitraums durch vielfältige Faktoren beeinflusst. Es durchlief Phasen mit Höhen und Tiefen, was es unmöglich macht, in diesem Rahmen alle Etappen und Facetten nachzuzeichnen. Stattdessen wird anhand ausgewählter Aspekte der Versuch unternommen, Schlaglichter auf das Verhältnis zu werfen und maßgebliche Einflussfaktoren zu beschreiben. Hierzu zählt sicherlich der Kirchenbesitz der Ritterorden, der in den unterschiedlichen Rechtsformen von Eigenkirchen über die Inkorporation bis hin zum Patronat dazu beitrug, Templer und Johanniter im Gefüge der kirchlichen Institutionen zu verankern. Daneben erlauben insbesondere die Rechtsprechung und Rechtswahrung Einblicke in das Verhältnis zwischen Ritterorden und den geistlichen Strukturen, in denen sie agierten, denen sie angehörten, die sie beeinflussten und von denen sie selbst geprägt wurden. Der Schwerpunkt liegt im Folgenden auf Akteuren aus den weltgeistlichen Hierarchien. Die dichte Ordens- bzw. Klosterlandschaft des Midi soll nicht berücksichtigt werden.

Neben den Gotteshäusern kann insbesondere die Exemtion der Ritterorden, die im Weiteren als Befreiung von der Jurisdiktionsgewalt der Bischöfe verstanden wird, als einer der wichtigsten Einflussfaktoren angesehen werden. Sie hatte weitreichende Folgen und griff wie kein zweites Privileg in die Vorrechte der regionalen amtskirchlichen Autoritäten ein. Ihre Bedeutung sollte allerdings nicht im Sinne einer absoluten Unabhängigkeit der Ritterorden überschätzt werden. Die Exemtion war zu keinem Zeitpunkt gleichbedeutend mit einer Autarkie der

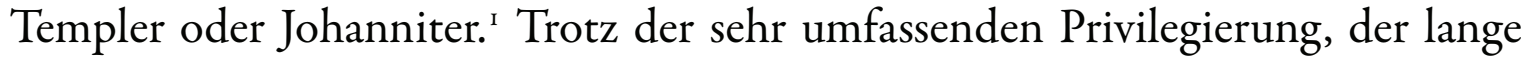
andauernden Förderung durch die Kurie sowie durch geistliche und weltliche Große und ungeachtet ihrer wirtschaftlichen wie politischen Potenz erreichten weder Templer noch Johanniter einen Status, der einer völligen Eigenständigkeit gleichgekommen wäre. Dies machte sich aus ihrer Sicht umso deutlicher bemerkbar, je größer die Entfremdung zu den Teilen der kirchlichen Strukturen wurde, auf die sie weiterhin angewiesen waren.

Die Ritterorden trafen bei ihrer Ankunft im Süden des heutigen Frankreich und in den folgenden Jahrzehnten, in denen sie sich ausbreiteten und etablierten, auf bereits bestehende und beständige kirchliche Strukturen. Dies unterschied die Region von den Grenzräumen der Ökumene, wo kirchliche Strukturen und Be-

I In Übereinstimmung mit der Definition des Begriffs im Duden, wird der Terminus Autarkie nicht auf die wirtschaftliche Eigenständigkeit verkürzt, sondern soll allgemeiner die Unabhängigkeit von äußeren Einflüssen und Mächten ausdrücken. Siehe: Art. "Autarkie," http://www. duden.de/rechtschreibung/Autarkie, zegegriffen am I s. Februar 20 I 9. 
ziehungsgeflechte noch aufgebaut oder gefestigt werden mussten und daher flexibler waren. Im Midi konnten Kirchenprovinzen, zahlreiche Bistümer, aber auch viele Klöster und Stifte und selbst einige Pfarrkirchen auf eine lange und teilweise illustre Geschichte zurückblicken. ${ }^{2}$ Die Strukturen, die sich bis zur Wende des I I. zum I 2. Jahrhundert herausgebildet hatten, erwiesen sich lange Zeit als äußerst stabil, da es nur im Fall des provenzalischen Orange zur Ausgründung einer Diözese (aus dem Bistum Saint-Paul-Trois-Châteaux) kam. Erst Papst Johannes XXII. nahm am Anfang des I 4. Jahrhunderts größere Eingriffe in die Bistumslandschaft des Languedoc vor, indem er die Kirchenprovinzen und Bistümer als Reaktion auf die Bekämpfung häretischer Bewegungen im I 3. Jahrhundert umfassend reorganisierte. ${ }^{3}$ Auf der darunterliegenden Ebene kam es durchaus noch zu Verschiebungen, indem das Netz an Pfarreien immer dichter wurde, um die Seelsorge zu intensivieren. Infolgedessen hatten sich die Ritterorden in ein bestehendes System einzufinden, das sie nur in Teilen - wenn überhaupt - mitgestalten konnten. Natürlich beeinflussten die Kommenden als geistliche Institutionen auf einem basalen Niveau die kirchlichen Strukturen in ihrem näheren geografischen, politischen, wirtschaftlichen und sozialen Umfeld. ${ }^{4}$ Allerdings boten den Kommenden selbst nur die Pfarreien Gestaltungsspielräume, da es den Ritterorden nicht gelang, einen Ordensbruder auf einen der Bischofsstühle des Midi zu bringen. Dabei ist hervorzuheben, dass die räumlichen Strukturen der Säkularkirche und diejenigen der Ritterorden zu keinem Zeitpunkt übereinstimmten. Weder orientierten sich die südfranzösische Ordensprovinz der Templer - die Provinz Provence und einige Teile Spaniens - oder das Johanniterpriorat St-Gilles an den Grenzen der Bistümer oder der Kirchenprovinzen. Noch folgten die geografischen Zuständigkeiten der Kommenden dem Zuschnitt der Pfarreien, in denen sie sich befanden. Dies führte dazu, dass Einflusssphären, geographische Interessensgebie-

2 Für eine Übersicht für die Bistumslandschaft der Provence siehe: Thomas Krämer, Dämonen, Prälaten und gottlose Menschen. Konflikte und ibre Beilegung im Umfeld der geistlichen Ritterorden, Vita Regularis, Abhandlungen 64 (Münster: Lit-Verlag, 20 I 5), Karte I.

3 Michelle Fournié, Fabrice Ryckebusch und Agnès Dubreil-Arcin, "Jean XXII et le remodelage de la carte ecclésiastique du Midi de la France. Une réforme discrète”, Revue d'Histoire Ecclésiastique 98 (2003): 29-35.

4 Zur Stellung der Ritterordenskommenden siehe: Jonathan Riley-Smith, "The Origins of the Commandery in the Temple and the Hospital," in La Commanderie. Institutions des ordres militaires dans l'Occident médiéval. Actes du premier colloque international du Conservatoire Larzac Templier et Hospitalier, "La commanderie, institution des ordres militaires dans l'Occident médiéval", tenu à Sainte-Eulalie-de-Cernon (Aveyron), du I 3 au Is octobre 20oo, hrsg. v. Anthony Luttrell und Léon Pressouyre, Mémoires de la Section d'Archéologie et d'Histoire de l'Art du CTHS 44 (Paris: CTHS, 2002), 9-I 3. 
te und die Horizonte der jeweiligen Akteure auf beiden Seiten stark divergierten, was sich als nachteilig erwies.

Dennoch kann nicht bezweifelt werden, dass Johanniter und Templer v. a. durch den regionalen Episkopat wohlwollend aufgenommen wurden. Die Gunst der Bischöfe und auch der Domkapitel äußerte sich in einer Reihe von Schenkungen, die teilweise unmittelbar zur Gründung von Kommenden führten. Diese Zuwendungen schlossen oft die Übertragung von Kapellen oder Pfarrkirchen mit ein. Schon der älteste Besitz der Templer auf europäischem Boden war die Kirche Saint-Barthélemy de la Motte-Palayson in der provenzalischen Diözese Fréjus. ${ }^{5}$ Das später so bedeutende Johanniterhaus in Manosque geht auf Bischof Gérard III. von Sisteron zurück, der dem Orden i I 55 die Kirchen St-Pierre de Manosque, Notre-Dame de Borra, St-Jean de Saumane, La Roche-Giron und StPierre des Omergues schenkte. ${ }^{6}$ Diese positive Einstellung zumindest von Teilen der regionalen Geistlichkeit äußerte sich nicht nur in den Übertragungen an sich, sondern floss in einigen Fällen auch in die Urkundentexte ein. So übereignete der Bischof des kleinen provenzalischen Bistums Vaison der Templerkommende Roaix, qui in nostro episcopatu gratia Dei est \& hedificatur, eine Insel im Fluss Ouvèze. ${ }^{7}$ Der Bischof von Carcassonne und sein Domkapitel verbanden ihre Schenkung mit der Hoffnung, dass die Templerbrüder von Douzens sich als aufrichtige und treue Freunde erweisen würden. ${ }^{8}$ Einige Geistliche sagten einem Ritterorden im Rahmen von Schenkungen oder deren Bestätigung ihre Unterstützung und ihren Schutz für die Ordensbrüder und deren Ländereien zu. So drohte Bischof Aldegaire von Albi in drastischen Worten allen, die die Unverletzlichkeit einiger

5 Zur Schenkung siehe: Cartulaire général de l’ordre du Temple i I Ig?-I Iso. Recueil des chartes et des bulles relatives à l'ordre du Temple, hrsg. v. Gustave A. M. d'Albon (Paris: Champion, I 9 I 3 ), Nr. II. Zu den Hintergründen siehe: Damien Carraz, Lordre du Temple dans la basse vallée du Rhône (II24-I3I2). Ordres militaires, croisades et sociétés méridionales, Collection d'Histoire et d'Archéologie médiévales 17 (Lyon: Presses Universitaires de Lyon, 2005), 87; Dominic Selwood, Knights of the Cloister. Templars and Hospitallers in Central-Southern Occitania c. IIoo-c. 1300 (Woodbridge: Boydell, I 999), 58.

6 Cartulaire général de l'ordre des Hospitaliers de Saint-Jean de Jérusalem (IIoo-I3Io), Bd. I, IIoo-I200, hrsg. v. Jean Delaville le Roulx (Paris: Champion, I 894), Nr. 230.

7 Cartulaires des Hospitaliers et des Templiers en Dauphiné, hrsg. v. Ulysee J. Chevalier (Vienne: Savigné, i 875 ), Nr. I I 5.

8 Cartulaires des Templiers de Douzens, hrsg. v. Paul Gérard und Élisabeth Magnou, Collection des Documents inédites sur l'Histoire de la France 3 (Paris: Bibliothèque Nationale, 1965), Cartulaire B, Nr. 9: ut vos et successores vestri sitis recti et fideles amici predicte Sancte Marie et clericis ibidem manentibus et clericis predicti Sancti Stephani presentibus ac futuris de aliis omnibus rectitudinibus sine inganno. 
Schenkungen an die Johanniter missachteten, das Anathem an. ${ }^{9}$ Diese Beispiele sollen genügen, um zu illustrieren, dass der höhere Klerus in weiten Teilen gegenüber Johannitern wie Templern ausgesprochen aufgeschlossen war. Ohne die Förderung durch die Bischöfe wären die Niederlassung und die Ausbreitung der Ritterorden in der Region nicht möglich gewesen. Damien Carraz bezeichnete den südfranzösischen Episkopat daher treffend als Schlüssel für die spirituelle Legitimation und zugleich den weltlichen Besitz des Templerordens im Midi. ${ }^{\circ}{ }^{\circ}$ Dies soll natürlich nicht bedeuten, dass Güter oder Gotteshäuser nicht auch durch Laien an einen der Ritterorden gekommen wären. So schenkte ein Toulousaner Bürger ca. I I 4 den Johannitern die Kapelle St-Rémi in der Stadt, die zur Keimzelle der zukünftigen Kommende wurde. ${ }^{11}$

$\mathrm{Zu}$ der frühen Förderung mag beigetragen haben, dass zumindest die Templer vergleichbar mit den Zisterziensern zu Vertretern der Kirchenreform gerechnet wurden. Familien, die diesen Vorstellungen besonders zugetan waren, finden sich häufig unter ihren Förderern, wie Jochen Schenk zeigen konnte. In vielen Fällen standen dieselben Familien der Kreuzzugsidee positiv gegenüber und konnten auf Kreuzzugsteilnehmer unter ihren Verwandten verweisen. ${ }^{12}$ Dies gilt ebenso für Vertreter des Episkopats, die sich selbst als Reformer hervortaten oder die Kirchenreform unterstützen. Zu diesem Personenkreis gehörte z. B. Pons de Grillon, Bischof von Saint-Paul-Trois-Châteaux, der sowohl die Templer in seiner Diözese ansiedelte, als auch die Zisterze Aiguebelle förderte. ${ }^{13}$ Im Zuge der Kirchenreform versuchte die regionale Geistlichkeit u. a., die Seelsorge zu intensivieren. Templer und Johanniter profitierten davon, indem man ihnen Pfarrkirchen und damit Aufgaben in der Betreuung der Gläubigen übertrug. Für die Geistlichen aus dem Welt- wie auch aus dem Regularklerus, die die Ritterorden in dieser Form förderten, war die Übertragung eines Gotteshauses nicht einfach eine Schenkung, die mit einem Gebäude oder einer Wiese vergleichbar gewesen wäre. Es bedeutete zum einen eine Anerkennung der noch jungen Gemeinschaften als spirituell verdienstvolle Institutionen mit einer akzeptierten Vokation. Zum anderen ent-

9 Gustave Saige, "De l'ancienneté de l'Hôpital Saint-Jean de Jérusalem. Donations dans l'Albigeois antérieures à la première croisade," Bibliothèque de l'École des Chartes 5 (I 864), 557: Domnus autem episcopus Aldegarius, qui Cruces ipsas firmavit, invasores et depredatores ipsius emunitatis gladii anathematis feriendo excomunicavit, et maledictioni qua Spiritus Sanctus per os Prophete et sanctuarii Dei possessores maledixit, illos subjecit. Eine genaue Datierung der Urkunde erweist sich als schwierig, da das angegebene Datum nicht mit der Bischofsliste übereinstimmt.

1o Carraz, L'ordre du Temple, I 33.

i Cartulaire général, hrsg. v. Delaville le Roulx, I, Nr. 35.

12 Jochen Schenk, Templar Families. Landowning Families and the Order of the Temple in France, c. II 20-I307 (Cambridge: Cambridge University Press, 20 I 2), I I 7- I 25.

I3 Carraz, L'ordre du Temple, I 34; Schenk, Templar Families, 80. 
standen durch Kirchen und Kapellen mehr als durch andere Übertragungen dauerhafte Beziehungen zwischen der lokalen Kirche und den begünstigten Orden bzw. Kommenden. Auf diese Weise trugen die Gönner wesentlich zur Integration der Ritterorden in die bereits bestehenden regionalen und lokalen kirchlichen Strukturen bei. Für die Ritterorden waren diese Gotteshäuser nicht nur wegen der Möglichkeit von Bedeutung, beständige Bande zur Ortskirche zu knüpfen. Durch Zehnte, Stolgebühren, Oblationen, Messen und weitere Einnahmequellen waren Pfarrkirchen ein wichtiger Faktor in der Ordenswirtschaft. Nicht zuletzt waren sie eine der wenigen Möglichkeiten, mit der Bevölkerung dauerhaft in Kontakt zu treten und ordensspezifische Sichtweisen und Anliegen zu propagieren, um zukünftige Zuwendungen zu fördern. ${ }^{14}$

Die Wohltäter aus dem Klerus waren sich der Implikationen und Vorteile für die Ritterorden sehr wohl bewusst, so dass sich viele im Rahmen der Schenkung bzw. der Bestätigung durch unterschiedliche Klauseln absicherten. Diese sollten sicherstellen, dass die übereigneten Oratorien, Kapellen und Kirchen nicht allzu eigenständig wurden und die bischöflichen Prärogativen gewahrt blieben. Zu diesen Vorsichtsmaßnahmen gehörte u. a. die Verpflichtung, einen Rekognitionszins an die zuständige Pfarrkirche bzw. an das Bistum abzuführen oder zu den Diözesansynoden zu erscheinen, womit symbolisch die Vorrangstellung der Ortskirche anerkannt werden sollte. ${ }^{15}$ Dem gleichen Zweck dienten Vorschriften zur Größe sowie zur Ausstattung der Ordenskirchen mit Glocken bzw. Kirchtürmen oder zum Glockengeläut. ${ }^{16}$ Derartige Bestimmungen fanden vereinzelt schon früh Eingang in die Urkunden, wurden aber tendenziell im Lauf der Zeit immer häufiger.

Für Norditalien hat Elena Bellomo eine weitere, interessante Begründung für die Großzügigkeit der Bischöfe zur Diskussion gestellt. Demnach seien derartige Schenkungen auch erfolgt, um Unterordnungsverhältnisse zu etablieren. Zwar sei der Templerorden an sich weiterhin exemt geblieben, aber durch die Zahlungsverpflichtungen an den Bischof und den Unterhalt für die Gotteshäuser seien die

14 Die Bedeutung des Niederkirchenwesen für die Ritterorden z. B. als Kontaktzone zur Bevölkerung und zur übrigen Geistlichkeit bedarf im Vergleich mit anderen Aspekten der Ordensgeschichte noch einer systematischeren Betrachtung.

is Derartige Bedingungen wurden z. B. in die Schenkungsverträge der Kirche von Nébian an die Johanniter aufgenommen: Cartulaire général, I, hrsg. v. Delaville le Roulx, Nr. 259 (28. Oktober I I 57). Siehe auch: Krämer, Dämonen, Prälaten, I 7 , I $32-135$.

16 Die Abtei St-Gilles machte den Johannitern exakte Vorgaben zur Größe des Glockenturms und des Friedhofs. Siehe: Cartulaire général, I, hrsg. v. Delaville le Roulx, Nr. 253; Cartulaire du prieuré de Saint-Gilles de l'hôpital de Saint-Jean de Jérusalem (II2g-I2Io), hrsg. v. Daniel Le Blévec und Alain Venturini (Paris: CNRS-Editions, I 997), Suppl. Nr. I: [...] oratorium longitudinis XII brachiatarum, amplitudinis IIIIor et totidem altitudinis scilicet IIIIor usque ad trabas [...] cui immineat campanile altitudinis unius brachiate. 
Kommenden vor Ort de facto an den Episkopat gebunden worden. ${ }^{17}$ Demnach sollten die Ritterorden nicht nur in die lokalen Strukturen integriert werden, sondern ihre Gönner beabsichtigten ebenso, ihnen durch die Bindung gleichsam Fesseln anzulegen. Es stellt sich allerdings die Frage, inwiefern solche Überlegungen nicht zu stark aus der Rückschau geprägt sind. Eine derartige Strategie bewusster „Danaer-Geschenke“ des Episkopats setzt voraus, dass die Ritterorden schlechter gestellt worden wären als andere geistliche Gemeinschaften, denen im gleichen Zeitraum Kirchen oder Kapellen übertragen wurden. ${ }^{18}$ Die bisherigen Forschungen haben zumindest keinen Hinweis auf ein solches Vorgehen in Südfrankreich ergeben.

Im Gegenteil belegt die Einbindung der südfranzösischen Ritterorden in die kirchliche Friedensbewegung klar das Ansehen, das sie fast das gesamte I 2. Jahrhundert im Midi genossen und das ihre Integration in die kirchlichen Strukturen beförderte. Ab I I 34 versuchten südfranzösische Bischöfe mehrfach, mit lokalen Initiativen an die Gottesfriedensbewegung anzuknüpfen, die um das Jahr ı 100 gewalttätige Übergriffe auf Wehrlose, Geistliche und kirchlichen Besitz sowie die ubiquitären Fehden des Adels eindämmen sollte. ${ }^{19}$ Um I I 40 - also nur sechzehn Jahre, nachdem die Templer die ersten Besitzungen im Midi erhalten hatten wurde der Ritterorden auch in diese Bewegung eingebunden. Wohl im Anschluss an eine Provinzialsynode verkündete der Erzbischof von Narbonne eine Treuga $D e i$, die von den weltlichen Großen der Umgebung - den Grafen von Toulouse und von Rodez sowie von dem Vizegrafen von Carcassonne - bestätigt wurde. Erstmals kamen auch die Templer in den Genuss der Bestimmungen, indem ihr Vieh und ihre Zugtiere sowie alle Menschen und Tiere, die zum Ackerbau vorgesehen waren, unter Schutz gestellt wurden. Die herausgehobene Stellung wurde

17 Elena Bellomo, The Templar Order in North-West Italy (II42 - c. 1330) The Medieval Mediterranean. Peoples, Economies and Cultures, 400- I 50072 (Leiden-Boston: Brill, 2008), I 48: „A link between Temple and episcopate may have been formed with the assigning of churches and hospitals. These assignments implied the creation of a subordinate relationship, albeit generally of a fiscal nature only, with the assigning bishop. The Templars continued to be exempt, but at the same time were bound by the bishop to carry out maintenance and repair work on the premises assigned to them and to pay an annuity for the investiture".

18 Zur Klärung dieser Frage wären weitere komparatistische Studien erforderlich, die die Ausbreitung verschiedener geistlicher Orden untersuchen.

19 Zur Gottesfriedensbewegung siehe: Werner Götz, "Kirchenschutz, Rechtswahrung und Reform. Zu den Zielen und zum Wesen der frühen Gottesfriedensbewegung in Frankreich," Francia I I (1983): 209; Lotte Kéry, Gottesfurcht und irdische Strafe. Der Beitrag des mittelalterlichen Kirchenrechts zur Entstehung des öffentlichen Strafrechts, Konflikt, Verbrechen und Sanktion in der Gesellschaft Alteuropas. Fallstudien ro (Köln-Weimar-Wien: Böhlau, 2006), I 39-1 47 . 
auch dadurch betont, dass die Templerbrüder eine eigens erhobene Steuer eintreiben sollten. ${ }^{20}$ I I 55 bestätigte Hadrian IV. die Bestimmungen und damit auch den Schutz für die Templer mit der Littera Sicut sacra evangelii, die allein im I 2. Jahrhundert mindestens elf Mal impetriert wurde. ${ }^{21}$ Die erhaltenen Exemplare stammen fast alle aus Archivbeständen der Templer oder der Johanniter und belegen, welch große Bedeutung die Ritterorden dem Rechtsinhalt der Papsturkunden beimaßen. Auch in den Kirchenprovinzen Bordeaux und Auch sowie im Bistum Béziers wurden Treugen verkündet und den Ritterorden in diesem Zusammenhang vergleichbare Aufgaben übertragen. ${ }^{22}$ Die geringen militärischen Kapazitäten der Ritterorden in der Region dürften dabei kaum ausschlaggebend gewesen sein, da weder die Templer noch die Johanniter der bäuerlichen Bevölkerung wirksamen Schutz hätten zukommen lassen können. ${ }^{23}$ Vielmehr dürfte die allgemeine Wertschätzung und die politische Neutralität in den zahlreichen Konflikten zwischen den weltlichen Großen des Midi bei gleichzeitig engen Beziehungen zu den Herrscherhäusern ausschlaggebend gewesen. Zwar entwickelten sich die Ritterorden im Midi nicht zu den veritablen „Instanzen der Friedenssicherung“, die sie nach Jochen Burgtorf in den Kreuzfahrerherrschaften darstellten. ${ }^{24}$ Im Unterschied zu den Verhältnissen in Outremer betraute der regionale Klerus Johanniter oder

20 Siehe hierzu: Damien Carraz, "Sub eiusdem pacis et treugue Dei defensione. Die Ritterorden und der Friede in Südfrankreich im I 2. Jahrhundert," Ordines Militares Colloquia Torunensia Historica. Yearbook of the Study of the Military Orders I 7 (20 I2): 25; Damien Carraz, "Les ordres militaires et la paix dans le Midi au XII siècle," Provence Historique 63, Nr. 252 (2013): 242; Damien Carraz, "Un revival de la paix de Dieu? Les paix diocésaines dans le Midi, In La reforme 'grégorienne’ dans le Midi, milieu XI' - début XIII' siècle, hrsg. v. Michelle Fournié (Toulouse: Privat, 2013): 534.

${ }_{21}$ Papsturkunden für Templer und Johanniter. Archivberichte und Texte, hrsg. v. Rudolf Hiestand, Vorarbeiten zum Oriens Pontificius I, Abhandlungen der Akademie der Wissenschaften in Göttingen, Philologisch-Historische Klasse, Dritte Folge 77 (Göttingen: Vandenhoeck \& Ruprecht, I 972), Nr. 27 (27. April I I 55), Nr. 34 (I. Januar I I 57-I I 59), Nr. 38 (2. Mai I I 62), Nr. 52 (3. August i I65), Nr. 54 (5. Juni I I 66-I I 67), Nr. 56 (26. Juli i I 68-i I 69), Nr. 75 (23. Juli I 173-I 176) mit Formularveränderung, Nr. 76 (25. Juli I 173-I 176) mit Formularveränderung, Nr. 2 I 8 (I 3 . April I I 90, Nr. 2 I 9 (I 6. April I I 90), Nr. 22 I (I 7. April I I 90).

22 Wie in Narbonne oblag es Johanniter- und Templerbrüdern, die im Rahmen der (erz-)bischöflichen Treuga Dei erhobenen Abgaben in den einzelnen Pfarreien einzutreiben. Vgl.: Carraz, Sub eiusdem pacis, 26; Cartulaire de la cathédrale de Dax. Liber rubeus (XI'-XII siècles). Texte édité, traduit et annoté, hrsg. v. Georges Pons und Jean Cabanot (Dax: Comité d'Études sur l'Histoire et l'Art de la Gascogne, 2004), Nr. I 42.

23 Für eine gegenteilige Einschätzung siehe: Carraz, Sub eiusdem pacis, 3 I.

${ }_{24}$ Jochen Burgtorf, "Die Ritterorden als Instanzen der Friedenssicherung?" in Jerusalem im Hoch- und Spätmittelalter. Konflikte und Konfliktbewältigung - Vorstellungen und Vergegenwärtigungen, hrsg. v. Dieter Bauer, Klaus Herbers und Nikolas Jaspert, Campus Historische Studien 29 (Frankfurt/Main-New York: Campus-Verlag, 200 I), I 74-I 80. 
Templer nur eingeschränkt mit friedenswahrenden Aufgaben. So erfolgte die Bestrafung von Friedensbrechern nach den Bestimmungen im Bistum Dax durch eine Kommission aus Bischöfen und Adeligen, der eine Untersuchung durch den jeweiligen Diözesan und Vertretern der Ritterorden vorausging. ${ }^{25}$ Dennoch sprechen diese Beispiele dafür, dass Adel wie Klerus beiden Ritterorden über Wohlwollen hinaus ein gewisses Vertrauen entgegenbrachten.

Die Ritterorden bewiesen ihrerseits eine bemerkenswerte Flexibilität, indem sie sich immer wieder den Bedingungen vor Ort anpassten. Dies betraf u. a. die Liturgie, die oft den regionalen und lokalen Gewohnheiten folgte und von den Traditionen im Heiligen Land abwich, wo die Gebräuche der Kanoniker vom Heiligen Grab verbindlich blieben. ${ }^{26}$ Für Europa wurden entsprechende Anpassungen sowohl für Italien, als auch für die Britischen Inseln und das Königreich Aragon beobachtet. ${ }^{27}$ Mit Blick auf das Vorgehen der Templer konstatierte Christina Dondi, dass die Übereinstimmung der Liturgie mit den Kanonikern vom Heiligen Grab nicht als wichtiger vereinigender Faktor oder als integraler Aspekt des Erbes angesehen wurde. ${ }^{28}$ Auch Südfrankreich bildete in dieser Hinsicht keine Ausnahme. Soweit die überschaubare Quellenbasis Rückschlüsse auf den Reliquienbesitz zulässt, versuchten die Ritterorden nur in vereinzelten Ausnahmefällen, eigene, lokale Kulte zu etablieren. Etwa in Manosque, wo ab den I $280 e r$ Jahren eine Kopfreliquie des angeblichen Ordensgründers der Johanniter, Gérard Tenque, verehrt wurde. ${ }^{29}$ Vielmehr knüpften die Ritterorden an etablierte Heilige und

25 Cartulaire de la cathédrale de Dax, hrsg. v. Pons und Cabanot, Nr. I 42. Siehe auch: Carraz, Sub eiusdem pacis, 32 .

26 Diese Abweichungen wurden bereits von Anne-Marie Legras beschrieben: Anne-Marie Legras and Jean-Loup Lemaitre, "Le pratique liturgique des Templiers et des Hospitaliers de Saint-Jean de Jérusalem," in L'écrit dans la société médiévale. Divers aspects de sa pratique du XI au XVe siècle. Textes en hommage à Lucie Fossier, hrsg. v. Caroline Bourlet und Anne Dufour (Paris: CNRS éditions, I 99 I), 8 I - I00.

27 Sebastián Salvadó, "Templar Liturgy and Devotion in the Crown of Aragon," in On the Margins of Crusading. The Military Orders, the Papacy and the Christian World, hrsg. v. Helen Nicholson (Farnham: Ashgate, 201 I ), 32; Christina Dondi, "Liturgies of the Military Religious Orders," in The Genius of the Roman Rite. Historical, theological and pastoral Perspectives on catholic Liturgy, hrsg. v. Uwe M. Lang (Chicago: Hillenbrand Books, 20 I0), i 47.

28 Dondi, Liturgies, 147.

$29 \mathrm{Zu}$ dem legendären Gründer des Hospitals und seiner Rolle im Midi siehe: Daniel Le Blévec, "Aux origines des Hospitaliers de Saint-Jean de Jérusalem: Gérard dit 'Tenque' et l'établissement de l'ordre dans le Midi," Annales du Midi 89, Nr. I 32 (I977), I $50-$ I 5 I. Alain Beltjens hat die Zuordnung der Reliquien zum legendären Ordensgründer infrage gestellt und sie Gérard d'Aurillac zugeschrieben. Siehe: Alain Beltjens, "Trois questions à propos de l'hospitalier Gérard," Bulletin de la Société de l'histoire et du patrimoine de l'Ordre de Malte I 9 (2007), 3-59; 20 (2008), 5-52. 
Reliquienkulte an. I286 übergab Guillaume de Villaret, Johanniter-Großprior von St.-Gilles, dem Johanniterhaus von Aix einen in Silber eingefassten Finger der heiligen Maria Magdalena und ein Bild der heiligen Veronica, ${ }^{30}$ die er aber einem Ordensbruder abgenommen hatte, der sie eigentlich in die Auvergne hatte bringen sollen. ${ }^{31}$ Aus den Inventaren, die bei der Verhaftung der provenzalischen Templer angefertigt wurden, geht hervor, dass zur Ausstattung der Templerkirche von Grasse ein Kreuzreliquiar mit Splittern des Wahren Kreuzes gehörte. ${ }^{32}$ Hinsichtlich der Patrozinien lassen sich kaum Auffälligkeiten ausmachen. Templerkirchen waren häufig der Jungfrau Maria oder Maria Magdalena geweiht, was natürlich kein Alleinstellungsmerkmal darstellt, da dies beispielsweise auch auf zahlreiche Zisterzienserkirchen zutraf. ${ }^{33}$

Auch beim Kirchenschmuck berücksichtigten die Ritterorden lokale Gegebenheiten. Das Dekor der Templerkirche in Montsaunès, die als Kommende- und als Pfarrkirche fungierte, gehört zu den ältesten erhaltenen Wandmalereien südfranzösischer Ritterordenskirchen. Das Programm verweist insofern auf die $\mathrm{Zu}$ gehörigkeit des Templerordens zur universalen, römischen Kirche, als die Apostel Petrus und Paulus dargestellt werden. Indem nicht etwa Szenen aus dem Leben, sondern das Martyrium der Apostel ebenso wie das des heiligen Stefan gezeigt wird, betonen die Malereien die Mission bzw. das Selbstverständnis des Ordens, als Beschützer der Heiligen Stätten das eigene Leben für den Glauben einzusetzen. ${ }^{34}$ Auch die Ausschmückungen der Johanniterkirche in Paulhac heben die Zugehörigkeit zur römischen Kirche hervor, allerdings gehen die Abbildungen stärker auf lokale Bezüge ein. Zum einen zeigt das Bildprogramm den ersten Bischof der Diözese, der als Apostel dargestellt wird, zum anderen mit Valeria die erste Märtyrerin Aquitaniens. ${ }^{35}$ Die Johanniterkirche war nicht die einzige im Midi, die den Diözesan derart ehrte. Auch ein Kapitell der Templerkirche im provenzalischen

30 L'histoire des grands prieurs et du grand-prieuré de St-Gilles, hrsg. v. Jean Raybaud, Supplément aux Mémoires de l'Académie de Nîmes 26 (Nîmes: Clavel \& Chastanier, I 904), I, 205.

${ }_{31}$ Cartulaire général, I, hrsg. v. Delaville le Roulx, Nr. 3797.

32 Joseph-Antoine Durbec, "Les Templiers dans les Alpes-Maritimes. Notice historique sur les maisons et possessions du Temple dans les diocèses de Antibes-Grasse, Nice, Vence et Glandève," in Templiers et Hospitaliers en Provence et dans les Alpes-Maritimes, hrsg. v. Joseph-Antoine Durbec (Grenoble: Mercure Dauphinois, 200 I), 263: Item, unam crucem parvam de argento, in qua est de ligno Sancte Crucis [...].

33 Carraz, Lordre du Temple, 330.

34 Cécile Voyer, "La pensée visuelle des Templiers et des Hospitaliers de Saint-Jean de Jérusalem au XIII siècle. Réflexions à partir du décor de quelques édifices du royaume de France," Cabiers de Civilisation Médiévale 59 (2016), 53-54.

35 Voyer, "La pensée visuelle," 56. 
Ruou zeigte einen Bischof mit zwei Akolythen, was auf die guten Beziehungen der Kommende zu den Bischöfen von Fréjus anspielen sollte. ${ }^{36}$

Gelegentlich reagierten die Ritterorden ebenso auf aktuelle Entwicklungen. Ein Beispiel wäre die Verehrung der heiligen Katharina von Alexandria, die im 1 3. Jahrhundert auch innerhalb der Ritterorden immer beliebter wurde. ${ }^{37}$ In Lavaufranche verbanden die Johanniter die Beliebtheit der Heiligen bildlich auf sehr geschickte Weise mit der Aufgabe des Heidenkampfs. Zwei unmittelbar angrenzende Abbildungen zeigen einerseits den Disput der heiligen Katharina mit vier heidnischen Gelehrten, während darunter ein gerüsteter und berittener Johanniter vier muslimische Reiter vertreibt. Die Symmetrie der Darstellungen und ihre Anordnung in der Kirche dürften kaum zufällig gewählt worden sein. ${ }^{3}$ So wie Katharina mit Worten gegen den Unglauben vorging, so kämpften die Ordensbrüder mit Waffen gegen die Heiden. Liturgie und Ausgestaltung der Gotteshäuser dienten somit mehreren Zwecken. Sie sollten dazu beitragen, den Gläubigen die Position der Ritterorden im Gefüge der Kirche zu vergegenwärtigen. Dabei wurde sowohl das Selbstverständnis als vollwertiger Orden der universalen Kirche, als auch die lokale Verwurzelung betont. Die Bildprogramme führten allen Besuchern die bewusste Integration der Orden in die lokalen und regionalen Strukturen sinnfällig vor Augen. Sie spiegelten zugleich die Spannung zwischen überregionaler und damit supradiözesaner Vokation mit der klaren Ausrichtung auf die Heiligen Stätten und der lokalen Verankerung in den Pfarreien und Diözesen im Westen, in der sich die Ordenshäuser und -provinzen permanent befanden. Die Kirchen und Kapellen der Ritterorden mussten beide Dimensionen angemessen berücksichtigen, da sie von den Ordensbrüdern ebenso besucht wurden wie von den Pfarrkindern und eventuellen Gönnern. Nicht zuletzt stammte die Mehrheit der südfranzösischen Ordensbrüder aus einem relativ begrenzten geographischen Umfeld der Kommenden und teilte somit die lokalen Präferenzen für bestimmte Heilige. ${ }^{39}$ Die Ritterorden konnten auf diese Weise auch einer wei-

36 Damien Carraz und Yoan Mattalia, "Images et ornements. Pour une approche de l'environnement visuel des ordres militaires dans le Midi (XII ${ }^{\mathrm{e}}-\mathrm{XIII} \mathrm{e}^{\mathrm{e}}$ siècle)," in Images et ornements autour des ordres militaires au Moyen Age. Culture visuelle et culte des saints (France, Espagne du Nord, Italie), hrsg. v. Damien Carraz und Esther Dehoux (Toulouse: Presses Universitaires du Midi, 2016), 54.

37 Zur Verehrung der heiligen Katharina in den Ritterorden siehe: Helen Nicholson, "Saints venerated in the Military Orders," in Selbstbild und Selbstverständnis der geistlichen Ritterorden, hrsg. v. Roman Czaja und Jürgen Sarnowsky, 9 I - I I 3 . Ordines Militares. Colloquia Torunensia Historica XIII (Toruń: Uniwersytet Mikołaja Kopernika, 2005), 9 I- I I 3.

38 Voyer, "La pensée visuelle," 68-69.

39 Zur Rekrutierung der südfranzösischen Templerbrüder siehe: Carraz, L'ordre du Temple, 288-302 . 
teren strukturellen Schwäche begegnen, die sie grundlegend von anderen geistlichen Institutionen unterschied. Ihre eigentlichen Leistungen und Verdienste für die Christenheit und die Kirche erbrachten Johanniter und Templer nicht in den europäischen Regionen, in denen sich der Großteil ihrer Besitzungen und die Rekrutierungszentren befanden, sondern in den Randgebieten der Ökumene. Diese Leistungen mussten den Gläubigen, die mit Ihren Zuwendungen den Kampf zum Schutz der Heiligen Stätten erst ermöglichten, immer wieder in Erinnerung gebracht werden. Auch den regionalen kirchlichen Akteuren, auf deren Unterstützung und Kooperation die Ritterorden angewiesen waren, mussten die Erfolge und Errungenschaften immer wieder vermittelt werden. Einer Pfarrkirche, einem Kloster, Stift oder Mendikantenkonvent fiel es deutlich leichter, den Sinn der jeweiligen Vokation und den spirituellen Gewinn einer Zuwendung zu vermitteln. Deren Tätigkeiten beschränkten sich in aller Regel auf einen begrenzteren geographischen Rahmen und waren daher für die Gönner eher erfahrbar. Somit zeigen Liturgie und Dekor zugleich, dass sich die Ordensbrüder des Umstands bewusst waren, dass die Kommenden im Westen in komplexe soziale und Macht-Systeme eingebunden blieben, die bisweilen nur schwer mit den formal existierenden Ordensprivilegien und v. a. der Exemtion in Einklang zu bringen waren.

Die bisher geschilderten Entwicklungen und Phänomene betrafen ausschließlich das I 2. Jahrhundert. Die in diesen Zeitraum fallende, schrittweise Integration der Ritterorden in die kirchlichen Strukturen Südfrankreichs war gleichzeitig Einbindung und ein sich-Einfinden. Einbindung, da weltgeistliche Institutionen die Ritterorden oft positiv aufnahmen und in einer Art und Weise unterstützten, die es den Ritterorden überhaupt erst ermöglichte, einen eigenen Platz im Gefüge zu finden. Es war zugleich ein aktives sich-Einfinden vonseiten der Ritterorden, da Johanniter und Templer ihrerseits gesetzte Rahmenbedingungen akzeptierten und flexibel auf regionale und lokale Gegebenheiten eingingen. Doch schon im letzten Viertel des Jahrhunderts begann sich das Verhältnis der Johanniter und Templer zu einem großen Teil der regionalen Geistlichkeit grundlegend zu wandeln. Insofern ist es kein Zufall, dass die Unterstützung und die Ausbreitung der beiden Ritterorden, die ihren deutlichsten Ausdruck in der Neugründung und dem Ausbau von Kommenden fand, an der Wende vom I 2. zum I 3. Jahrhundert ins Stocken geriet..$^{40}$ In der Folgezeit gelang es beiden Ritterorden immer seltener, neue Ordenshäuser aufzubauen oder bestehende Kommenden um Kapellen oder Kirchen zu erweitern. Des Weiteren wurden die Bedingungen, die an die Neugründung

40 Siehe: Selwood, Knights of the Cloister, 49-71; Damien Carraz, "Templiers et Hospitaliers en France méridionale (XII $-\mathrm{XIII}$ e siècles). À propos d'un ouvrage récent," Provence Historique 50, Nr. 200 (2000), 2 I 8-228; Carraz, L'ordre du Temple, 90- I07 
eines Ordenshauses oder seinen Ausbau verknüpft wurden, immer detaillierter und aus Sicht der Ritterorden tendenziell zunehmend härter. Beispielsweise behielt sich das Domkapitel von Montpellier bzw. Maguelone zahlreiche Rechte und Abgaben vor und schränkte die Bestattungserlaubnis des Templer- sowie des Johanniterhauses in Montpellier stark ein. ${ }^{41}$ Eine Ausnahme stellt die Templerkommende in Avignon dar, die erst 1273 geschaffen wurde. Bezeichnenderweise war dazu die Vermittlung des dortigen Bischofs erforderlich, der die Interessen der Templer und des Domkapitels auszugleichen hatte. Beide Seiten hatten zuvor Prokuratoren beauftragt, die in ihrem Namen die Verhandlungen führen sollten. Das Ergebnis war eine Abmachung, die die Rechte und Pflichten der Ordensbrüder gegenüber der Kirche von Avignon detailliert festhielt..$^{42}$ Der Aufwand, der betrieben wurde, um dieses Ergebnis zu erreichen und der Umfang sowie die Tiefe der Regelungen stehen im Gegensatz zu den wesentlich einfacheren Übertragungen des I 2. Jahrhunderts. Sie spiegeln das zwischenzeitlich gewachsene Misstrauen wider, sind aber auch auf allgemeine Tendenzen der Zeit zurückzuführen, etwa die gestiegene Bedeutung des römisch-kanonischen Rechts. ${ }^{43}$ Auch die Anzahl der Streitigkeiten um die Rechtsstellung einzelner Kirchen und Kapellen, der dort angestellten Priester sowie um die Verpflichtung zu Abgaben und Dienstleistungen an die Pfarr- und Bischofskirchen stieg im Laufe der Zeit an. An dieser Stelle kann auf diese Entwicklungen nicht weiter eingegangen werden. ${ }^{44}$ Sie waren nicht zuletzt Ausdruck sich wandelnder wirtschaftlicher Rahmenbedingungen, die die Bedeutung von Pfarreien und Kirchen als Einkommensquelle durch Messen, Jahrtagsfeiern, Bestattungen und Stolgebühren anwachsen ließ.45 Die Gotteshäuser

41 Vgl.: Krämer, Dämonen, Prälaten, 193-194, 264-265. Die Vereinbarungen zwischen den Ritterorden und der Kirche von Maguelone/Montpellier sind ediert in: Cartulaire de Maguelone, Tl. I, hrsg. v. Jean Rouquette und André Villemagne (Montpellier: Valat, I 9 I 4), Nr. 257 ; Tl. II, hrsg. v. Jean Rouquette und André Villemagne (Montpellier: Valat, I 9 I 4), Nr. 280.

42 Regest: Gallia Christiana Novissima, Tl. VII, Avignon, hrsg. v. Joseph H. Albanès und Ulysee Chevalier (Valence: Imprimerie Valentinoise, I 920), Nr. 7 I 7. Edition: Damien Carraz, "Ordres militaires, croisades et sociétés méridionales. L'ordre du Temple dans la basse vallée du Rhône (I I 24-I 3 I 2)" (Thèse de doctorat nouveau régime Université Lyon II, 2003), III, CTAv, Nr. 66. Zum gesamten Vorgang siehe: Krämer, Dämonen, Prälaten, 37-38.

43 Zur Ausbreitung des römisch-kanonischen Rechts und zur wachsenden Bedeutung siehe: André Gouron, "Les étapes de la pénétration du droit romain au XII ${ }^{e}$ siècle dans l'ancienne Septimanie," Annales du Midi 69 (1957): 103; André Gouron, "Diffusion des consulats méridionaux et expansion du droit romain aux XII e et XIII" siècles," in La science du droit dans le Midi de la France au Moyen Age, hrsg. v. André Gouron, Collected Studies Series 196 (London: Variorum Reprints, 1984), Aufsatz I, 26-76.

44 Vergleiche hierzu: Krämer, Dämonen, Prälaten, ı 8- I 44.

45 Jacques Chiffoleau, "Sur l'économie paroissiale en Provence et en Comtat Venaissin du XIII ${ }^{e}$ au XV ${ }^{\mathrm{e}}$ siècle," in La Paroisse en Languedoc (XIII ${ }^{e}-X I V^{e}$ siècles), hrsg. v. Marie-Humbert Vicaire 
der Ritterorden entwickelten sich dadurch von einem Bindeglied zur regionalen Geistlichkeit zunehmend zu einem Stein des Anstoßes.

Suchte ein Bischof vor diesem Hintergrund nach Möglichkeiten, auf einen der Ritterorden Einfluss zu nehmen, sah er sich zunächst mit dessen herausgehobener Stellung im Kirchenrecht konfrontiert. Dennoch betonte kürzlich Helen Nicholson, dass die Ritterorden zwar exemt waren, dass sie aber de facto weder von weltlichen Mächten, noch von lokalen geistlichen Autoritäten, Bischöfen und Erzbischöfen unabhängig gewesen seien. ${ }^{46}$ Daher hätten Johanniter und Templer Kompromisse eingehen müssen, indem sie z. B. weltlichen Herrschern Einfluss auf die Besetzung von Leitungsfunktionen in den Orden zugestanden..$^{47} \mathrm{Im}$ Vergleich zur Reichweite von Entscheidungen weltlicher Herrscher wie dem Kaiser oder dem französischen König, die sich auf eine Vielzahl von Kommenden auswirkten, war der potenzielle Schaden, den ein Bischof anrichten konnte, geringer. Dennoch konnte die Gegnerschaft eines Diözesans für eine Kommende oder eine Ordensprovinz immense Nachteile mit sich bringen. Die Macht eines Bischofs gründete v. a. auf seiner Amtsgewalt, die ihrerseits auf drei Säulen beruhte: der Weihe-, der Lehr- und der Jurisdiktionsgewalt. Die Privilegien der Ritterorden, aber auch das konkrete Vorgehen der Ordensbrüder tangierten jede dieser Säulen, allerdings in unterschiedlichem Ausmaß. Umgekehrt war nicht jeder Aspekt der bischöflichen Vollmachten gleich gut geeignet, eine Kommende unter Druck zu setzen. In den folgenden Ausführungen wird zunächst der Kirchenbesitz im Vordergrund stehen, bevor die Exemtion näher betrachtet werden soll.

Grundsätzlich war die Weihe von Kirchen, Altären und Friedhöfen den zuständigen Diözesanbischöfen oder ihren Delegaten vorbehalten. ${ }^{48}$ Für einen exemten Orden war die Befreiung von dieser Bindung von herausgehobener Be-

(Toulouse: Privat, I 990), 98-ı 105; Jacques Chiffoleau, "Les transformations de l'économie parroisiale en Provence (XIII $-\mathrm{XV}^{\mathrm{e}}$ siècles)," in La parrocchia nel medio evo. Economia, scambi, solidarita, hrsg. v. Agostino Paravicini-Bagliani und Véronique Pasche, Italia Sacra. Studi et Documenti di Storia Ecclesiastica 53 (Rom: Herder, 1995), 66-67.

46 Helen Nicholson, "Nolite confidere in principibus. The Military Orders' Relations with the Rulers of Christendom," in Élites et ordres militaires au Moyen Age. Rencontre autour d'Alain Demurger, hrsg. v. Philippe Josserand, Luis F. Oliveira und Damien Carraz, Collection de la Casa de Velázquez i 45 (Madrid: Casa de Velázquez, 2015), 261: „Yet, whatever their privileges in theory, in practice the military orders were not independent of secular powers, nor of the local ecclesiastical authorities, bishops and archbishops".

47 Nicholson, "Nolite confidere," 267-268.

48 Georg Schreiber, Kurie und Kloster im I2. Jahrhundert. Studien zur Privilegierung, Verfassung und besonders zum Eigenkirchenwesen der vorfranziskanischen Orden vornehmlich aufgrund der Privilegien von Paschalis II. bis auf Lucius III. (I09g-II 8 I), Bd. II (Stuttgart: Ferdinand Enke, 1910), 179-209. 
deutung, um das mit ihr einhergehende Abhängigkeitsverhältnis zu vermeiden. Forderte ein Bischof anlässlich der Weihe einen Gehorsamseid, konnte er letztlich die Exemtion untergraben. ${ }^{49}$ Die Entwicklung der Privilegienformulare ist in dieser Hinsicht aufschlussreich. Die frühen Exemplare des Templerprivilegs Omne datum optimum enthielten noch keine eindeutigen Bestimmungen zur Weihe von Kirchen, Altären usw. Es ist daher davon auszugehen, dass die Templer die Weihegewalt des Ortsbischofs zu achten hatten. Nach dem III. Lateranum, in dessen Verlauf es zu massiven Klagen gekommen war, wurde das gesamte Formular des Templerprivilegs in wichtigen Punkten verändert. Für die Weihe der Kirchen und Altäre wurde der Orden in der neuen Ausfertigung von I 179 zunächst an den zuständigen Ortsbischof verwiesen. Diese hatten die Weihehandlungen ohne finanzielle Gegenleistung oder falsche Forderungen vorzunehmen. Allerdings änderte die Kurie nur kurze Zeit nach dem Konzil die Formulierung ab, indem die Zuständigkeit schlicht Diözesanbischöfen übertragen wurde. Was wie eine grammatikalische Petitesse anmutet, hatte weitreichende Konsequenzen, da die Templer nun allgemein auf Bischöfe, aber nicht mehr zwangsläufig auf den Ortsbischof angewiesen waren. Allerdings blieb dieser der erste Ansprechpartner. Erst wenn er sich weigerte oder Gegenleistungen verlangte, konnten sich die Ordensbrüder auch an andere wenden..$^{50}$ Bemerkenswerterweise enthielt das Johanniterprivileg Christiane fidei religio den Verweis auf den Ortsbischof bereits seit i 54 und damit 25 Jahre vor den Templern. Dies gilt auch für den Zusatz, dass sich die Ordensbrüder im Falle einer Weigerung mit einem anderen Konsekrator behelfen konnten. ${ }^{\text {II }}$ Die Weihegewalt des Ortsbischofs war somit ausgehöhlt, wenngleich sich die Frage stellt, welcher Bischof das Risiko einging, die Beziehungen zu einem Amtsbruder massiv zu belasten, indem er in dessen Diözese Weihehandlungen vornahm. Weigerte sich dagegen ein Ortsbischof, verstieß er unter Umständen

49 Lotte Kéry, "Klosterfreiheit und päpstliche Organisationsgewalt. Exemtion als Herrschaftsinstrument des Papsttums?" in Rom und die Regionen. Studien zur Homogenisierung der lateinischen Kirche im Hochmittelalter, hrsg. v. Jochen Johrendt und Harald Müller, Abhandlungen der Akademie der Wissenschaften in Göttingen, N.F. I 9 (Berlin, Boston: de Gruyter, 2012), 108-109.

so $\mathrm{Zu}$ Omne datum optimum siehe: Papsturkunden für Templer und Johanniter. Neue Folge, hrsg. v. Rudolf Hiestand, Vorarbeiten zum Oriens Pontificius II, Abhandlungen der Akademie der Wissenschaften in Göttingen, Philologisch-Historische Klasse, Dritte Folge I 35 (Göttingen: Vandenhoeck \& Ruprecht, I 984), I oo. Letztendlich lautete die vollständige Formel: Consecrationes uero altarium seu basilicarum [...] et cetera ecclesiastica sacramenta a diocesanis suscipatis episcopis, si quidem catholici fuerint et gratiam atque communionem apostolice sedis habuerint et ea gratis et absque pranitate aliqua uobis uoluerint exhibere. Alioquin liceat uobis catholicum, quemcumque malueritis, adire antistitem. Zur Formularentwicklung: ebd., 91 .

s1 Ebd., I 35. 
gegen päpstliche Privilegien und lief Gefahr, dass ein anderer Diözesan um die Weihe gebeten wurde. So beanspruchte 1290 der Bischof des provenzalischen Gap eine finanzielle Entschädigung für die Weihe einer Kirche und belegte die Johanniterkommende mit dem Interdikt, nachdem diese die Zahlung verweigert hatte. ${ }^{22}$ Da die Ausbreitung der Ritteroden ab dem I 3. Jahrhundert ebenso wie der Ausbau der Kommenden mit Kirchen und Friedhöfen zunehmend stockte, gab es immer seltener Anlässe für derartige Machtproben. Wie andere exemte Gemeinschaften auch werden die Ritterorden meist dazu übergegangen sein, ungeachtet ihrer Vorrechte den jeweiligen Diözesan um die Vornahme von Weihehandlungen zu bitten. ${ }^{33}$

Auch aus der Lehrgewalt ergaben sich Ansatzpunkte für bischöfliche Einflussnahmen. Die Aufnahme von Geistlichen in den Templerorden war seit I I 39 bzw. bei den Johannitern seit I I 54 nicht mehr von der Zustimmung des Ortsbischofs abhängig. ${ }^{54}$ Diesem stand kein Aufsichtsrecht zu, da die Geistlichen dem Ordensmeister unterstellt waren, und er konnte die präsentierten Kandidaten nicht ablehnen, solange diese rechtgläubig waren oder kein kanonisches Hindernis vorlag. 5 s Diese Ausgliederung der Geistlichen aus dem Diözesanverband war auf den kleinen Kreis des Ordensklerikats eng begrenzt und galt nicht für alle Priester, die an Kirchen und Kapellen des Ordens Dienst verrichteten. ${ }^{6}$ Priester, Vikare und Kapläne an Patronats- oder inkorporierten Kirchen gehörten nicht automatisch zum Kreis der exemten Ordensbrüder und mussten somit weiterhin dem Ortsbischof

52 Appellation des Johanniterpräzeptors von Gap an den Erzbischof von Aix wegen der Forderungen des Bischofs von Gap, 23. Juli I 290, siehe: Marseille, Archives Départementales des Bouches-du-Rhône, $56 \mathrm{H} 4624$.

53 Georg Schreiber hatte dies bereits für andere exemte Orden herausgearbeitet: Schreiber, Kurie und Kloster, I: 176.

s4 Zum Ordensklerikat siehe: Jürgen Sarnowsky, "The Priests in the Military Orders. A comparative Approach on their Standing and Role," in On the Military Orders in medieval Europe. Structures and Perceptions, hrsg. v. Jürgen Sarnowsky, Collected Studies Series CS 992 (Farnham-Burlington: Variorum Reprints, 20 I I ), Aufsatz XVIII, $2-3$.

ss Christian Vogel, Das Recht der Templer. Ausgewählte Aspekte des Templerrechts unter besonderer Berücksichtigung der Statutenhandschriften aus Paris, Rom, Baltimore und Barcelona, Vita Regularis, Abhandlungen 33 (Münster: Lit-Verlag, 2007), 176.

s6 In einer Dekretale hatte bereits Innozenz III. in einer Streitsache des Klosters Evesham entsprechend entschieden. Siehe: Corpus iuris canonici, Pars II, Decretalium collectiones. Decretales Gregorii P. IX., Liber sextus decratalium Bonifacii P. VIII., Clementis P. V. constitutiones, extravagantes tum viginti Ioannis P. XXII. tum communes, editio Lipsiensis secunda post Aemilii L. Richteri, instr. Aemilius Friedberg (Lipsiae: B. Tauchnitz, I 88 I (Nachdruck: Graz: Akademische Druck- u. Verlagsanstalt, I959)), X.5.33.17. Vgl. dazu auch: Jane Sayers, "The Proprietary Church in England. A Note on Ex ore sedentis (X.5.33.17)," Zeitschrift der Savigny-Stiftung für Rechtsgeschichte. Kanonistische Abteilung 74 ( I988), 23 I-245. 
präsentiert werden, der ihre Eignung prüfte sowie ihnen gegebenenfalls die cura animarum verlieh. Des Öfteren hatten sich die Diözesane derartige Regelungen bei der Übertragung der Kirchen explizit ausbedungen. Daraus ergab sich, dass sie dem Bischof zu Gehorsam verpflichtet waren, zur Synode erscheinen mussten und die Kirchen visitiert werden durften. ${ }^{57}$ Bereits im I 2. Jahrhundert wurden Klagen laut, dass die Ritterorden ungenügende Kandidaten präsentierten oder eigenmächtig Priester ein- und absetzten, was schließlich auch auf dem III. Laterankonzil im Jahr I 79 thematisiert wurde. ${ }^{8}$ In einigen Fällen scheint es zu drastischen Vorfällen gekommen zu sein. Der Liber Extra enthält eine Littera Alexanders III. an die Johanniter, der ihnen verbot, Exkommunizierte an ihren Kirchen einzusetzen.99 Umgekehrt ermahnte die Kurie den Episkopat im I 3. Jahrhundert immer wieder, Kandidaten der Templer oder Johanniter zu akzeptieren, da ansonsten Pfarreien unbesetzt blieben und die Seelsorge litt. ${ }^{60}$ Derartige Vorkommnisse sind für Südfrankreich nur durch Papsturkunden überliefert und lassen alleine keine Aussagen zum Ausmaß oder zur Tragweite etwaiger Vorkommnisse zu. Hinweise auf konkrete Fälle, die tiefere Einblicke gewähren könnten, fehlen bislang. Ungeachtet der Qualifikation der Präsentierten könnten beide Seiten ein Interesse an einer Ablehnung gehabt haben. Den Johannitern war es seit 12 I 7 gestattet, Einnahmen aus vakanten Pfarreien zum Wohle des Heiligen Landes einzusetzen. ${ }^{61}$ Die Gelder kamen nicht mehr wie eigentlich vorgesehen, den Pfarreien zugute, sondern konnten „umgenutzt" werden. Allerdings konnte eine Kommende das Präsentationsrecht verlieren, wenn die Pfarrei nicht innerhalb von sechs Monaten besetzt wurde. In diesen Fällen stand dem Ortsbischof das Besetzungsrecht zu, der die Stelle einem eigenen Kandidaten zuweisen durfte. ${ }^{62}$ Angesichts der Vielzahl von Beschwerden, die an der Kurie über die jeweilige Gegenseite vorgebracht wurden, kann davon

57 Siehe hierzu: Krämer, Dämonen, Prälaten, i I.

58 Dekrete der ökumenischen Konzilien, Vol. II, Konzilien des Mittelalters vom ersten Laterankonzil (II23) bis zum fünften Laterankonzil (ISI2-ISI7), hrsg. v. Giuseppe Alberigo (Paderborn-München: Schöningh, 2000), 2 16, can. 9.

59 Corpus iuris canonici, II, instr. Friedberg, X.3.38.1 3.

60 Schon 1217 hatte Honorius III. auf Klage der Johanniter entsprechende Vorwürfe gegenüber dem Klerus geäußert: Regesta Honorii Papae III iussu et munificentia Leonis XIII Pontificis Maximi ex Vaticanis archetypis, I, hrsg. v. Pietro Pressutti (Rom: Loescher, I 888), Nr. 239; Cartulaire général de l'Ordre des Hospitaliers de S. Jean de Jérusalem (IIoo-I310), II, I200-I260, hrsg. v. Joseph Delaville Le Roulx (Paris: Ernest Leroux, I 897), Nr. I 529 (I6. Januar I 217).

61 Cartulaire général, II, hrsg. v. Delaville le Roulx, Nr. I 32 (2 I. Juli I 2 I 7 ).

62 Corpus iuris canonici, II, instr. Friedberg, X.3.38.22. Siehe auch: Josef Ahlhaus, Geistliches Patronat und Inkorporation in der Diözese Hildesheim im Mittelalter (Freiburg/Breisgau: Waibel, I 927), I 23. 
ausgegangen werden, dass sowohl beide Ritterorden als auch der Episkopat ihre jeweiligen Vorrechte und Kompetenzen gelegentlich überschritten. Der allmähliche Wandel im Verhältnis zwischen Ritterorden und den weltgeistlichen Strukturen lässt sich klar nachvollziehen. Im I 2. Jahrhundert bezogen die Bischöfe die Ritterorden noch in ihre Bemühungen ein, die Seelsorge im Midi zu intensivieren, indem man ihnen Kirchen übertrug. Im I 3. Jahrhundert trat dieser Aspekt klar in den Hintergrund, insofern aus der Kooperation zunehmend ein Konkurrenzverhältnis wurde. Dem Episkopat waren durch die angedrohte Ablehnung eines Kandidaten oder seiner tatsächlichen Zurückweisung, die mit dem Verlust von Rechten und Einkünften verbunden sein konnte, durchaus Möglichkeiten an die Hand gegeben, eine Kommende empfindlich zu treffen.

Am stärksten griffen die Privilegien der Johanniter und Templer in die Jurisdiktionsvollmachten der Bischöfe ein. Die Exemtion beider Orden, die die Johanniter ab I 53 innehatten und die Templer erst I 179 definitiv erreichten, schloss viele Einflussmöglichkeiten der Ortsbischöfe aus. Sie konnten keine Kirchenstrafen verhängen, Kommenden visitieren oder nur unter bestimmten Bedingungen Ordensbrüder zum Besuch der Diözesansynode verpflichten. Diese Vorrechte ließen sich nur schwer mit dem tradierten kirchlichen Gewohnheitsrecht in Einklang bringen, das im I 3 . Jahrhundert zunehmend kodifiziert wurde. Diese Kompilationen wurden auch mit der Intention verfasst, die Rechte und die Stellung der Bischofs- und Pfarrkirchen in einer Diözese zu wahren und zu betonen. ${ }^{63}$ Dieses Spannungsverhältnis blieb den Rechtsgelehrten der Zeit nicht verborgen. Die Kanonisten des I 3. Jahrhunderts versuchten mit großem Aufwand, den Missbrauch päpstlicher Privilegien zu unterbinden. Fehlerhafte oder unzulässige Interpretationen der kurialen Bevollmächtigungen konnten nicht nur dazu führen, Konflikte und Zwietracht in der Kirche zu schüren. Vielmehr war zu befürchten, dass eine wesentliche Säule des kanonischen Rechts und letzten Endes auch das Amt des Papstes beschädigt werden könnte. Daher sollten Privilegien immer eng ausgelegt und nicht stillschweigend durch eine immer umfassendere Auslegung erweitert werden. Der potenzielle Schaden, der durch den Rechtsinhalt des Privilegs Dritten zugefügt werden könnten, sollte auf diese Weise minimiert werden. ${ }^{64}$ Der Versuch der Johanniter und Templer, die Exemtion schrittweise auszudehnen, lief dieser Vorgabe diametral entgegen. Ursprünglich waren nur die Ordensbrüder und die familia von der bischöflichen Jurisdiktion ausgenommen. Im nächsten Schritt ver-

${ }_{63}$ Joseph Avril, "Mort et sépulture dans les statuts synodaux du Midi de la France," in La mort et l'au-delà en France méridionale (XII $-X I V^{e}$ siècles), Cahiers de Fanjeaux 33 (Toulouse: Privat, I 998), 348.

64 Richard H. Helmholz, Kanonisches Recht und europäische Rechtskultur. Mit einem Vorwort von Peter Landau (Tübingen: Mohr Siebeck, 20 I 3), 355-36 I. 
suchten die Orden, Angehörige der Bruderschaften, die confratres bzw. consorores und Donaten schützen zu lassen. Diese Bestrebungen verursachten derart viele Konflikte, dass schließlich das IV. Laterankonzil I 2 I 5 den Kreis der Privilegierten definierte und mit hohen Vorbedingungen verknüpfte. ${ }^{65}$ Dennoch beschäftigten sich südfranzösische Provinzialsynoden in der Folge mehrfach mit dieser Problematik. Dies mag damit in Zusammenhang stehen, dass die Ritterorden in Kooperation mit der Kurie andere Personenkreise sukzessive aus der Strafgewalt der Bischöfe herauslösten. Bereits wenige Jahre nach dem Laterankonzil setzte eine Serie von Papsturkunden ein, die zunächst Hintersassen und Arbeiter, dann diejenigen, die Ordensmühlen und Backöfen nutzten sowie Gönner und Wohltäter von der bischöflichen Jurisdiktion ausnahm. Letztendlich waren sogar Menschen eximiert, die mit einem der Ritterorden lediglich in geschäftlichem Kontakt standen. ${ }^{66}$ Als Begründung für jeden dieser Schritte führten die Päpste an, dass die Bischöfe Kontaktpersonen der Ritterorden mit Kirchenstrafen belegten, da sie die Ordensbrüder selbst nicht treffen konnten. Durch den Umgang mit Exkommunizierten wären Templer oder Johanniter selbst der Strafe anheimgefallen.

Aus dem Vorgehen der Ritterorden und der bischöflichen Reaktion resultierten eine Vielzahl von Papsturkunden, was den Rechtsgelehrten des I 3. Jahrhunderts nicht entging. Es ist daher bezeichnend, dass im Titel „Von den Privilegien und den Exzessen derer, die Privilegien innehaben" des Liber Extra sich nicht weniger als neun von 32 Papsturkunden auf Johanniter oder Templer beziehen. ${ }^{67}$ Nicht in allen aufgeführten Fällen waren es die Ritterorden, die wegen Übergriffen ermahnt wurden. In einer Dekretale drohte Alexander III. dem Episkopat sogar den Entzug der päpstlich verliehenen Rechte an, sollten die Privilegien der Johanniter weiter missachtet werden.$^{68}$ Dennoch waren beide Orden die am häufigsten genannten Gemeinschaften in diesem Abschnitt. Man könnte dies als Zufall, Einzelmeinung oder als ordensfeindliche Einstellung des Kompilators Raimund de Peñaforte abtun, der keine weitere Relevanz beizumessen sei. Allerdings ist eine dezidiert ritterordenskritische Haltung des Dominikaners bislang nicht bekannt. ${ }^{69}$

65 Dekrete der ökumenischen Konzilien, II, hrsg. v. Alberigo, 26 I, can. 57.

66 Cartulaire général, II, hrsg. v. Delaville le Roulx, Nr. 1704 (8. Januar I 22 I), Nr. I 894 ( I o. November I 227); Cartulaire général de l'Ordre des Hospitaliers de S. Jean de Jérusalem (II00-I3IO), Bd. III, I26I-I300, hrsg. v. Joseph Delaville Le Roulx (Paris: Ernest Leroux, I 899), Nr. 3 I 87 (24. Oktober I 265), Nr. 4335 (3 I. Januar I 297). Siehe auch: Krämer, Dämonen, Prälaten, I 54.

${ }_{67}$ Corpus iuris canonici, II, instr. Friedberg, X.5.33.3, 4, 5, 7, I O, I I, I 5, $20,24$.

68 Ebd., X.5.33.4.

$69 \mathrm{Zu}$ dem Juristen siehe: Thomas Wetzstein, "Resecatis superfluis? Raymund von Peñafort und der Liber Extra," Zeitschrift der Savigny-Stiftung für Rechtsgeschichte. Kanonistische Abteilung 92 (2006), 355-391. 
In einem Bereich blieben aber auch die Ritterorden auf die Gerichtsbarkeit der Diözesane angewiesen. Das privilegium canonis schrieb vor, dass sich diejenigen, die sich schwerer Vergehen an Geistlichen oder kirchlichem Besitz schuldig gemacht hatten, vor geistlichen Gerichten zu verantworten hatten. Dies galt ungeachtet des Umstands, ob der Angreifer Laie oder Geistlicher war. Die örtliche Zuständigkeit des Gerichts richtete sich nach dem Beklagten. ${ }^{70}$ Wurde eine Ritterordenskommende oder ein Ordensbruder bedrängt, mussten sich die Vertreter des betroffenen Ordens daher an den Bischof der Diözese wenden, aus der der Übeltäter stammte. Die Strafen für Übergriffe wurden durch das kanonische Recht vorgegeben und traten seit dem II. Lateranum I 39 ipso facto ein, also durch die Tat selbst und mussten nicht eigens verhängt werden. ${ }^{71}$ Eine Übereinkunft zwischen den Parteien war in diesen Fällen nicht möglich, da ein Geistlicher nicht selbst auf das Privileg verzichten konnte. Ein Urteil und dessen Verkündigung durch ein geistliches Gericht waren daher unumgänglich. ${ }^{72}$ Zusätzlich hatte Alexander III. bestimmt, dass diejenigen, die Templer oder Johanniter gewaltsam angingen, der Exkommunikation verfielen. ${ }^{73}$ Der Aufgabe, Täter zu ermitteln, Verfahren durchzuführen und die Schuldigen zu verurteilen, scheinen sich die Bischöfe bzw. ihre Gerichtsbeamten in den Augen der Johanniter und Templer nur widerwillig oder nachlässig angenommen zu haben. Bereits ab I I 44 finden sich Wendungen in Papsturkunden, die den Episkopat aufforderten, die Templer vor Übergriffen und Rechtsverletzungen zu schützen. ${ }^{74}$ Es ist allerdings unwahrscheinlich, dass der Ritterorden bereits zu einem so frühen Zeitpunkt Anfeindungen in größerem Ausmaß ausgesetzt war. Doch schon Alexander III. promulgierte ab i i 60 eine hohe Zahl von Litterae, die den Episkopat aufforderten, beide Ritterorden zu schützen. ${ }^{75}$ Die Vielzahl der Wiederholungen zeigt, dass der Erfolg dieser Aufrufe

70 Zum privilegium canonis siehe: Kéry, Gottesfurcht, 60 I-607. Das privilegium canonis ist nicht $\mathrm{zu}$ verwechseln mit dem privilegium fori, das geistliche Gerichte für straffällig gewordene Geistliche vorschrieb. Siehe: ebd., 60 I.

${ }_{71}$ Dekrete der ökumenischen Konzilien, II, hrsg. v. Alberigo, can. I 5 ( I I 39).

72 Kéry, Gottesfurcht, 604.

73 Für die Templer erging die Littera Paci et quieti: Papsturkunden für Templer und Johanniter. Archivberichte und Texte, hrsg. v. Hiestand, Nr. 70 (2 I. April I I 60- I I 76). Für die Johanniter promulgierte die Kurie mit gleichem Rechtsinhalt die Littera Quanto maior ab: Cartulaire général, I, hrsg. v. Delaville le Roux, Nr. 290 (9. März i I 60- I I 78).

74 Papsturkunden für Templer und Johanniter. Archivberichte und Texte, hrsg. v. Hiestand, Nr. I 9: Preterea fraternitati vestre rogando mandamus, quatinus personas eorum et bona pro caritati beati Petri et nostra manuteneatis et nullam ei irrogari lesionem uel iniuriam permittatis.

75 Für die Johanniter: Cartulaire général, I, hrsg. v. Delaville le Roulx, Nr. 290 (9. März I I 60- I 178 ). Für die Templer: Papsturkunden für Templer und Johanniter. Archivberichte und Texte, hrsg. v. Hiestand, Nr. 70 ( I. Juni I I 60-1 1 76). 
begrenzt war. Aus den allgemein gehaltenen Formulierungen lassen sich jedoch keine Hinweise auf konkrete Vorfälle ableiten. Klare Belege für eine mangelnde Unterstützung, die aus Gleichgültigkeit oder Gegnerschaft resultierte, haben sich seltener erhalten. Dabei konnte es vorkommen, dass selbst gewaltsame Übergriffe nicht verfolgt oder geahndet wurden.

I 286 überfielen einige Einwohner der provenzalischen Küstenstadt Antibes die Ländereien der Templerkommende Biot, fällten Bäume, entführten Vieh und misshandelten zwei Templerbrüder. Der Präzeptor wandte sich daraufhin an den Richter von Grasse, brachte seine Vorwürfe sowie Zeugen vor und benannte mehrere der Übeltäter. Gegen die daraufhin einsetzenden Untersuchungen protestierte der Bischof des Ortes mit dem Hinweis, dass ihm die Jurisdiktion zustehe. ${ }^{76}$ Der Richter unterließ aufgrund dieser Intervention weitere Nachforschungen mit der Begründung, er fürchte die Exkommunikation durch den Bischof. Offenbar unternahm dieser aber keine weiteren Anstrengungen, gegen die Übeltäter vorzugehen. I 288, zwei Jahre nach den Vorfällen, bat der Präzeptor von Biot den Richter von Grasse erneut um Schutz vor den Einwohnern von Antibes. ${ }^{77}$ Dagegen haben sich Quellen, die eine Verfolgung der Delinquenten durch den Bischof belegen, nicht erhalten. Inwiefern sein eventuelles Ignorieren der Vorfälle weitere Übergriffe erst ermöglichte, indem es die Bewohner von Antibes ermunterte, muss daher Spekulation bleiben. Dessen ungeachtet lässt sich festhalten, dass derartige Übergriffe zwar selten, aber keine singulären Ereignisse waren.

Auch um solchen Vorfällen entgegenzuwirken, ging das Papsttum dazu über, delegierte Richter zu bestellen, die Streitigkeiten vor Ort beilegen sollten. Dazu stattete die Kurie die ausgewählten Personen mit umfangreichen Vollmachten aus, um den Amtsträgern eine entsprechende Autorität zu verschaffen. ${ }^{7}$ Doch auch diese Delegaten waren bis zu einem gewissen Grad auf die Mitarbeit lokaler geistlicher und weltlicher Institutionen angewiesen. I 289 hatte der Propst von Orange als Konservator der provenzalischen Templer mehrere Geistliche exkommuniziert, ohne dass die verhängten Kirchenstrafen Wirkung gezeigt hätten. Im Gegenteil lasen einige der namentlich aufgeführten Kleriker aus dem Bistum Agde sogar weiterhin die Messe. Der Konservator im mehr als I 50 Kilometer entfernten

76 Schreiben des Vogts und königlichen Richters in Grasse, I. Januar I 286, siehe: Nizza, Archives Départementales des Alpes-Maritimes, G o 92.

77 Joseph-Antoine Durbec, "Monographie de Biot. Histoire et géographie humaine (Documentation inédite)," Annales de la Société scientifique et littéraire de Cannes et de l'arrondissement de Grasse N.S. 7 (1935), I 89.

78 Zur Entstehung der Delegationsgerichtsbarkeit siehe: Harald Müller, Päpstliche Delegationsgerichtsbarkeit in der Normandie (I2. und frühes I 3. Jahrbundert), T1. I, Studien und Dokumente zur Gallia Pontificia 4 (Bonn: Bouvier, I 997), 9- I 8. 
Orange bat daher Vertreter des Domkapitels von Agde, notfalls mit Hilfe des weltlichen Arms die Kirchenstrafen vor Ort bekannt zu machen und durchzusetzen. ${ }^{79}$ Ohne diese Unterstützung konnten offensichtlich nicht einmal die Templer und der Konservator gemeinsam genug Einfluss ausüben, um eine Anerkennung der Kirchenstrafen zu erreichen.

Doch auch bei päpstlichen Delegaten konnte es im Einzelfall vorkommen, dass sie ihren Auftrag nicht mit dem nötigen Nachdruck verfolgten. Im Streit um die Burg Manciet wurden zwischen I 239 und 1265 insgesamt drei Mal delegierte Richter bestellt. Ein kleiner, lokaler Ritterorden, die fratres paci et fidei, hatten die Burg okkupiert, die gemäß einer testamentarischen Verfügung an die Templer und Johanniter fallen sollte. Beide Ritterorden appellierten in der Folge gemeinsam an den Papst. Da die kleine Gemeinschaft, die später im Santiago-Orden aufging, die Urteile päpstlich delegierter Richter ignorierte und die Herausgabe der Burg verweigerte, wurde die Exkommunikation ausgesprochen, die allerdings den Widerstand nicht brechen konnte. ${ }^{80}$ Letzten Endes wurden die Sentenzen auch von Teilen der Geistlichkeit selbst missachtet. Papst Clemens IV. musste 1265 den Abt von Saint-Sernin in Toulouse anweisen, die Exkommunikationssentenz zu beachten, die dessen Vorgänger zwölf Jahre zuvor gefällt hatte. ${ }^{8 \mathrm{I}}$ Während sich der Toulousaner Abt mangelndes Engagement vorwerfen lassen musste, lässt das Verhalten anderer hochrangiger Geistlicher auf eine eindeutige Verweigerung gegenüber dem päpstlichen Auftrag schließen. So musste Papst Nikolaus IV. den Bischof von Rodez zwei Mal anschreiben, um ihn aufzufordern, den Abt von Saint-Gilles nach Rom zu laden. Dieser hatte den Ordenshäusern der Johanniter und Templer in seiner Stadt schwer zugesetzt, wobei er zum Teil Gewalt eingesetzt hatte. Dabei stützte er sich auf eine päpstliche Littera, die die Exemtion der Ritterorden de facto aufhob. ${ }^{82}$ In dem zweiten Schreiben wurde der Bischof mit der Suspension bedroht, sollte er der kurialen Weisung weiterhin nicht nachkommen. Dies ist umso erstaunlicher, als es sich bei dem Adressaten um Raymond de Calmont d'Olt handelte, der sich als Kanonist einen Namen gemacht hatte. ${ }^{83}$ Letztendlich half die Delegationsgerichtsbarkeit den Ritterorden nur bedingt, da die delegier-

79 Schreiben des Propsts von Orange an den Offizial von Agde, I 2. Februar I 289, siehe: Toulouse, Archives Departementales de la Haute-Garonne, H 120.

8o Krämer, Dämonen, Prälaten, 389.

81 Cartulaire générale, III, hrsg. v. Delaville le Roulx, Nr. 3 I 62 ( 13 . Juni I 265).

82 Siehe zu dieser Auseinandersetzung: Krämer, Dämonen, Prälaten, I 38 - 44.

83 Cartulaire générale, III, hrsg. v. Delaville le Roulx, Nr. 4096 (I 3. Mai I 290). Zum Bischof siehe: Joseph Avril, "Sources et caractères du livre synodal de Raimond de Calmont d'Olt, évêque de Rodez ( I 289)," in L'église et le droit dans le Midi (XII -XIV siècles), Cahiers de Fanjeaux 29 (Toulouse: Privat, I 994), 2 I 5-222. 
ten Richter, Konservatoren, usw. auch aus der Region und somit aus kirchlichen Strukturen vor Ort stammten. Verschlechterte sich das Verhältnis zum regionalen Klerus, wurde es immer schwerer, Personen zu finden, die als Delegaten der Kurie Beschwerden der Ritterorden aufnahmen und ihre Rechte sowie Interessen schützten. Die Alternative, in Rom Klage zu führen, war mit einem hohen Zeitund Kostenaufwand verbunden, wobei die Durchsetzbarkeit der kurialen Entscheidungen vor Ort nicht garantiert war. ${ }^{84}$

Bei der Rechtswahrung und Rechtsdurchsetzung blieben die Ritterorden de jure sowie de facto somit für alle Zeitgenossen sichtbar auf die geistlichen Strukturen vor Ort angewiesen. Nicht nur in dieser Hinsicht wirkte es sich negativ aus, dass die Ritterbrüder überwiegend aus dem mittleren und niederen Adel stammten und sich Vertreter hochadeliger Familien des Midi nur selten nachweisen lassen. ${ }^{85}$ Dadurch verringerte sich die Möglichkeit, über verwandtschaftliche Verbindungen Einfluss zu nehmen oder Netzwerke zu bilden. Im Gegensatz zu den lateinischen Bistümern in den Kreuzfahrerherrschaften erhielten die Ritterordensbrüder des Weiteren keinen Zugriff auf eines der südfranzösischen Bistümer. ${ }^{86}$ Selbst der Umstand, dass die Präzeptoren nicht verpflichtet waren, selbst auf den Diözesansynoden zu erscheinen, brachte Nachteile mit sich. Ein Austausch zwischen den Entscheidungsträgern der Ritterorden und der weltkirchlichen Hierarchien, der für ein gegenseitiges Verständnis und eine dauerhafte, tiefere Integration unabdingbar gewesen wäre, wurde auf diese Weise erschwert.

Die kurialen Versuche, den Schutz der Orden durch Litterae oder Delegaten sicherzustellen, erzielten nicht die gewünschte Wirkung, da sie die Kooperation des Klerus voraussetzten. Die Kurie ging jedoch nie so weit, die Jurisdiktionsvollmachten der Bischöfe in ihren Diözesen weiter als durch die Exemtion vorgegeben einzuschränken. So blieben Brüder und familia zwar vor bischöflichen Sentenzen und Eingriffen in das Ordensgefüge weitestgehend geschützt, liefen dadurch aber gleichzeitig Gefahr, dass sich der Episkopat zuweilen nicht besonders zu ihrem Schutz engagierte. Wie weit die Entfremdung fortgeschritten war, lässt sich daran ablesen, dass Bischöfe negative Konsequenzen ihres Handelns für sich selbst und die Bischofskirche in Kauf nahmen. Kamen sie ihren Pflichten, die sich aus dem

${ }_{4}$ Zum Verhältnis Aufwand und Ertrag von Prozessen an der Kurie siehe: Harald Müller, "Streitwert und Kosten in Prozessen vor dem päpstlichen Gericht - eine Skizze," Zeitschrift der Savigny-Stiftung für Rechtsgeschichte. Kanonistische Abteilung 87 (2001 ), I 62.

8s Carraz, L'Ordre du Temple, 292.

$86 \mathrm{Zu}$ den Kreuzfahrerherrschaften siehe: Rudolf Hiestand, “Templer- und Johanniterbistümer und -bischöfe im Heiligen Land," in Ritterorden und Kirche im Mittelalter, hrsg. v. Zenon H. Nowak, Ordines Militares. Colloquia Torunensia Historica IX (Toruń: Uniwersytet Mikołaja Kopernika, I 997), I 62- I66. 
privilegium canonis ergaben, nicht nach, riskierten sie den Unmut der Kurie, die größere Anstrengungen einforderte. Vor allem litt jedoch das Bild der Bischöfe, der Ritterorden und der Gesamtkirche bei den weltlichen wie geistlichen Zeitgenossen vor Ort, wenn sie ihre Pflichten nicht erfüllten.

Für die Templer und Johanniter wirkte sich diese Abhängigkeit von den Diözesanen und ihren geistlichen Gerichten umso schwerwiegender aus, da Rechtsinstitute wie die Vogtei oder Schutzherrschaft durch weltliche Große, wie sie für Deutschordenskommenden im Reich überliefert sind, in Südfrankreich unbekannt waren. ${ }^{87}$ Die Vogtei war in ihrer Ausprägung eine Besonderheit des Reichs, die im westlichen Europa keine Entsprechung hatte. ${ }^{88}$ Ohnehin war es Templern und Johannitern durch das römisch-kanonische Recht nur in engen Grenzen gestattet, sich an weltliche Große oder Gerichte zu wenden, um dort den Schutz von Personen oder Besitz zu erwirken. Das kanonische Recht sah diese Möglichkeit nur vor, wenn geistliche Gerichte kein Urteil fällen konnten. ${ }^{89}$ Dennoch kam es vor, dass eine Kommende ein weltliches Gericht einschaltete, wenn sie ihre Rechte verletzt sah. I 260 klagten die Templer vor dem königlichen Seneschall des Rouergue, dass Henri, der Sohn des Grafen von Rodez, mit einer großen Zahl von Bewaffneten gewaltsam in das Ordenshaus eingedrungen sei und dabei den Präzeptor und einige Brüder verletzt habe. Danach habe er Tiere gestohlen und sie zur Burg von Creyssels oder von Cornus getrieben..$^{90}$ Nur wenige Jahre später klagte die Kommende Biot vor dem gräflichen Richter von Draguignan gegen den Bischof von Fréjus, der ebenfalls eine Viehherde entführt haben sollte und sich weigerte, die Tiere herauszugeben. ${ }^{91}$ Die Unsicherheit, die mit dieser Situation einherging, mag dazu beigetragen haben, dass sich die Ritterorden gegenüber weltlichen Gro-

87 Zur Vogtei meist laikaler Stifter oder weltlicher Großer siehe: Peter C. von Planta, Adel, Deutscher Orden und Königtum im Elsaß des I3. Jahrhunderts unter Berücksichtigung der Johanniter, Freiburger Beiträge zur mittelalterlichen Geschichte 8 (Frankfurt/Main u. a.: Peter Lang, 1997), 25-26; ders., "Advocacy and ,defensio" - the Protection of the Houses of the Teutonic Order in the Region of the Upper Rhine during the thirteenth and fourteenth Centuries," in The Military Orders, vol. 6,2, Culture and Conflict in Western and Northern Europe, hrsg. v. Jochen Schenk und Mike Carr (London-New York: Routledge, 20 17), I 94- 99.

88 Charles West, "Monks, Aristocrats, and Justice: Twelfth-Century Monastic Advocacy in a European Perspective," Speculum 92, Nr. 2 (2017), 388-402.

89 Othmar Hageneder, Die geistliche Gerichtsbarkeit in Ober- und Niederösterreich von den Anfängen bis zum Beginn des Is. Jahrhunderts, Forschungen zur Geschichte Oberösterreichs 10 (Graz: Böhlau, i 967), i 4 I.

90 Antoine-Régis Carcenac, Les Templiers du Larzac. La commanderie du Temple de Sainte-Eulalie de Larzac (Nîmes: Lacour, 1994), 232.

91 Schreiben des Richters von Draguignan an den Bischof von Fréjus, I7. Oktober I 269, siehe: Gallia Christiana Novissima, Tl. I, Aix, Apt, Fréjus, Gap, Riez et Sisteron, hrsg. v. Joseph H. Albanès und Ulysee Chevalier (Montbéliard: Hoffmann, I 899), Sp. 2 I Nr. XXV. 
ßen eher zu Zugeständnissen bereitfanden oder bereitfinden mussten. Das enge Verhältnis zwischen den provenzalischen Johannitern und den Grafen der Provence aus dem Haus Anjou, deren Expansionsbestrebungen der Ritterorden in Süditalien unterstützte, wurde durch die Forschung bereits mehrfach betont. ${ }^{92}$ Es ist nicht auszuschließen, dass der Ritterorden damit ein Gegengewicht zum oder einen Ersatz für den regionalen Klerus aufbauen wollte, auf dessen Unterstützung er sich nicht mehr verlassen konnte oder wollte. Durch die Annäherung an das Haus Anjou war der Orden eher in der Lage, seine Position in den angevinischen Territorien in der Provence und in Süditalien abzusichern. Angesichts der im gesamten Midi verteilten Ordensbesitzungen reichte die Unterstützung einer Dynastie aber nicht aus. Im Languedoc gingen ab der Mitte des I 3. Jahrhunderts einige Johanniterkommenden sog. Paréage-Verträge mit der französischen Krone ein, die auch andere geistliche Institute abschlossen. ${ }^{93}$ Diese sahen u. a. vor, dass der König Ländereien geistlicher Institutionen unter seinen Schutz nahm. Dafür standen ihm verschiedene Gegenleistungen zu. In einem Prozess vor dem königlichen Seneschall von Carcassonne reichten die Johanniter beispielsweise ein Schreiben ein, dass dem königlichen Beamten den Schutz der Ordensgüter durch die Krone mitteilte. ${ }^{94}$ Offenbar war man zu der Überzeugung gekommen, nur noch auf diese Weise die eigenen Rechte und Besitzungen wahren zu können. Allerdings brachten die Allianzen mit weltlichen Großen Verpflichtungen mit sich, die wie-

92 Damien Carraz, "Christi fideliter militantium in subsidio Terre Sancte. Les ordres militaires et la première maison d'Anjou ( I 246-I 342)," in As Ordens Militares e as Ordens de Cavalaria entre $o$ Ocidente e o Oriente. Actas do V Encontro sobre Ordens Militares, hrsg. v. Isabel C. Fernandes (Palmela: Camara Municipal, 2009), 55 I-576; ders., "Pro servitio maiestatis nostre. Templiers et hospitaliers au service de la diplomatie de Charles Ier et Charles II," in La diplomatie dans les états angevins aux XIII et XIV siecles. Diplomacy in the Countries of the Angevin Dynasty in the thirteenth - fourteenth Centuries. Actes du colloque international de Szeged, Visegrád, Budapest, 13-I6 septembre 2007, hrsg. v. Zoltán Kordé und Istvan Petrovics (Rom-Szeged: Accademia d'Ungheria in Roma, 20 I0), 24-3 I; Christian Guzzo, "The Hospitallers and Charles I of Anjou. Political and economic Relations between the Kingdom of Sicily and the Holy Land," in The Military Orders, Vol. V, Politics and Power, hrsg. v. Peter Edbury (Aldershot: Ashgate, 2012), ro5-I I2; Michel Hébert, "Autour de la cavalcade: les relations entre le comte de Provence, les Hospitaliers et la commune de Manosque (XIII ${ }^{\mathrm{e}}-\mathrm{XIV}{ }^{\mathrm{e}}$ siècles)," in Vie privée et ordre public à la fin du Moyen Age. Études sur Manosque, la Provence et le Piémont (I250-I450), hrsg. v. Michel Hébert (Aix-en-Provence: Université de Provence, I 987), I 42 - I 44.

93 Zur Paréage siehe: Henri Gilles, "Paréage," in Lexikon des Mittelalters, Bd. VI (München: Artemis und Winkler 1993), Sp. I703; Robert Holtzmann, Französische Verfassungsgeschichte von der Mitte des neunten Jahrhunderts bis zur Revolution (München-Berlin: R. Oldenbourg, I 9 I 0 (Nachdruck: Darmstadt: WBG, I965)), I9I-192.

94 Libell zu einem Prozess zwischen dem Domkapitel Carcassonne und den Johannitern vor dem königlichen Richter ( 13 I 2-I 3 I 4), siehe: Toulouse, Archives Départementales de la Haute-Garonne, $\mathrm{H}$ i 28 , fol. $4 \mathrm{v}-5 \mathrm{r}$. 
derum zu Problemen mit der Kirche führen konnten.95 Darüber hinaus mussten die Ritterorden Zugeständnisse machen, die von Einflussnahmen auf Ämterbesetzungen bis hin zu konkreten Unterstützungsleistungen reichen konnten. Die große Johanniterkommende Manosque musste sich schließlich gegenüber den angevinischen Grafen der Provence zur Heerfolge verpflichten. ${ }^{96}$ Von einer Integration in die geistlichen Strukturen Südfrankreichs kann vor diesem Hintergrund nur noch bedingt gesprochen werden. Das sich-Einfinden der Ritterorden und die Einbindung durch die regionale Geistlichkeit, die noch im I 2. Jahrhundert zu beobachten war, kann für das fortschreitende i 3 . Jahrhundert immer seltener konstatiert werden.

Zusammenfassend lässt sich festhalten, dass die Integration und der Aufstieg der Ritterorden in Südfrankreich ohne oder gegen die regionalen kirchlichen Strukturen nicht möglich gewesen wären. Die Ritterorden akzeptierten die Rahmenbedingungen, die sie bei ihrer Ankunft und Ausbreitung in der Region vorfanden, und gingen zumindest teilweise flexibel auf lokale Gegebenheiten ein. Diese Phase der Kooperation hinterließ sichtbare Spuren: zum einen die zahlreichen Übertragungen von Gotteshäusern an Templer oder Johanniter bzw. die Ausgestaltung der Kirchen durch die Ritterorden. In diese Phase fiel auch eine $\mathrm{Zu}$ sammenarbeit im Bereich der Rechtsfindung und -wahrung durch die Einbindung in die bischöflichen Friedensinitiativen der Treuga Dei. Einer Vertiefung oder dauerhaften Einbindung waren aber durch gegenläufige Interessen Grenzen gesetzt. Der Fokus der lokalen und regionalen Geistlichen lag auf ihrem geographischen und geistlichen Zuständigkeitsbereich, während die Ritterorden zwei „Horizonte“ zeitgleich berücksichtigen mussten. Das lokale Umfeld der Kommenden, die weiterhin sowohl in kirchliche als auch in soziale und wirtschaftliche Strukturen eingebunden waren. Aus Sicht des Gesamtordens war und blieb es aber die Haupt-

95 Konstellationen, die mit der Exkommunikation Kaiser Friedrichs II., die v. a. den Deutschen Orden in eine schwierige Situation brachte, vergleichbar wären, sind für Südfrankreich nicht überliefert. Vgl. z. B.: Nicholas Morton, "Institutional Dependency upon secular and ecclesiastical Patrons and the Foundations of the Trial of the Templars," in The Debate on the Trial of the Templars (1307-1317), hrsg. v. Jochen Burgtorf, Paul Crawford und Helen Nicholson (Farnham-Burlington: Ashgate, 2010), 36-40. Allerdings handelten sich Templer und Johanniter während der Albigenserkreuzzüge den Vorwurf der Untätigkeit vonseiten einiger Geistlicher ein, obwohl sich Parteinahmen zugunsten der nordfranzösischen Kreuzzugsteilnehmer nachweisen lassen. Vgl.: Étienne Delaruelle, "Templiers et Hospitaliers en Languedoc pendant la Croisade des Albigeois," in Paix de Dieu et Guerre Sainte en Languedoc au $13^{e}$ siècle, Cahiers de Fanjeaux 4 (Toulouse: Privat, I 969), 3 1 5-334; Alan Forey, "The Military Orders and the War against Christians in the I 3 th century," English Historical Review I04 (1989), 10; Carraz, L'ordre du Temple, $43 \mathrm{I}$.

96 Hébert, Autour de la cavalcade, I 42-I 44. 
aufgabe der Ordenshäuser im Westen, Überschüsse zu erwirtschaften und Personal bereitzustellen, um den Kampf in den Kreuzfahrerherrschaften fortführen zu können. Die Folgen dieser immer deutlicher werdenden Grundkonstellation treten bei der Betrachtung der Exemtion klar hervor. Sie wirkte sich unmittelbarer als andere Vorrechte auf das Verhältnis zu regionalen kirchlichen Autoritäten aus. Umgekehrt eigneten sich die bischöflichen Jurisdiktionsbefugnisse besser als die Weihe- und Lehrgewalt, um Einfluss auf die Ritterorden auszuüben. Diese weiteten - auch auf diesen äußeren Druck hin - den Kreis der vor episkopalen Ansprüchen geschützten Personen immer weiter aus. Damit untergruben sie - ob gewollt oder nicht - die Stellung der Amtskirche. Diese reagierte u. a. damit, dass sie den Templern und Johannitern den Schutz versagte, der ihnen durch das im Kirchenrecht verankerte privilegium canonis zugestanden hätte. Auf diese Weise hatte die Autarkie der Templer und Johanniter eine Grenze gefunden, die die Exemtion und die übrigen Privilegien nicht beseitigen konnten. Im Gegenteil wirkte sich die Exemtion auf lange Sicht desintegrierend aus. Für den Schutz der eigenen Rechte, des Besitzes und der Ordensangehörigen blieben die Ritterorden auf die regionalen geistlichen Autoritäten angewiesen. Als Folge dieser schrittweisen Desintegration und sie verstärkend wandten sich die Ritterorden weltlichen Großen bzw. Amtsträgern zu. Eine völlige Herauslösung der Ritterorden aus den kirchlichen Strukturen war aber schon aufgrund des Kirchenbesitzes nicht möglich, der sie weiterhin an die Diözesen band.

Die Entfremdung zwischen den Templern bzw. Johannitern und Teilen des Klerus war bereits im zweiten Drittel des I 3. Jahrhunderts so manifest, dass die Johanniter schon für das II. Konzil von Lyon I 274 eine Verteidigungsstrategie vorbereiteten. ${ }^{97}$ In der Replik, die vermutlich von einem Johanniterbruder im Outremer verfasst wurde, bildete das Misstrauen und die Ablehnung der Geistlichkeit gegenüber Johannitern und Templern eine der Grundsäulen gegen die seit Jahren kursierenden Pläne, Johanniter und Templer zu vereinigen. Neben einer Reihe von mehr oder weniger belastbaren Argumenten gegen eine Union der beiden Ritterorden, brachte die Denkschrift erst gegen Ende ein Argument, dass zwar

97 Der Text wurde ursprünglich den Templern zugeschrieben: Paul Amargier, "La défense du Temple devant le concile de Lyon en I 274," in I274. Année charnière. Mutations et continuitées, hrsg. v. Centre National de Recherche Scientifique (Paris: Editions du CNRS, i 977), 495-500. Alan Forey konnte aber zeigen, dass der Autor unter den Johannitern gesucht werden sollte: Alan Forey, "A Hospitaller Consilium ( 1274 ) and the Explanations advanced by Military Orders from Problems confronting them in Holy Land in the later thirteenth Century," Ordines Militares Colloquia Torunensia Historica. Yearbook for the Study of the Military Orders 16 (20 I I) (Die Ritterorden in Umbruchs- und Krisenzeiten / The Military Orders in Times of Change and Crisis): 7-I 3 . 
als Vorteil einer Vereinigung bezeichnet wurde, dass aber in den Ohren des Klerus wie eine Drohung klingen musste: Angesichts der vielfachen Schädigungen, die sowohl Templer als auch Johanniter durch Laien wie Geistliche erführen, fiele es einem vereinten Ritterorden viel leichter, seine Rechte gegenüber jedermann zu verteidigen. ${ }^{9}$ Zwar präsentierte die Denkschrift die Aussage als Eingeständnis, dass eine Fusion vielleicht doch Vorteile haben könnte. Dennoch verbarg sich dahinter eine Drohung. Der unbekannte Verfasser ging davon aus, dass die Anspielung verstanden würde und dass die vereinigte Macht der beiden Ritterorden das letzte war, was die viele Prälaten wollten. Im Rahmen einer breit angelegten Abwehrstrategie gegen Kritik vonseiten des Klerus setzte der Johanniterorden beinahe als Selbstverständlichkeit voraus, dass die Ablehnung gegen eine vereinigte Macht so weit verbreitet und so manifest war, dass sie als wirksame Waffe gegen eine Union genutzt werden konnte. Offensichtlich schätzte der Ritterorden die Situation realistisch ein. Den Untergang des Templerordens konnte man mit dieser geschickten Argumentation freilich nicht aufhalten. Auf dem Konzil von Vienne zeigte die überwiegende Mehrheit der versammelten Geistlichen eine lavierende Reaktion oder eine bestenfalls verhaltene Unterstützung für die Templer. Gleichzeitig wurden Forderungen nach einer Aufhebung aller Johanniterprivilegien inklusive der Exemtion laut. Beides zeigt, wie weit und tiefgreifend die Entfremdung bereits fortgeschritten war. ${ }^{99}$

\section{PRIMARY SOURCES:}

Marseille. Archives Départementales des Bouches-du-Rhône, $56 \mathrm{H} 4624$.

Nizza. Archives Départementales des Alpes-Maritimes, G o 192.

Toulouse. Archives Départementales de la Haute-Garonne, H I 20, H 128.

Cartulaire de la cathédrale de Dax. Liber rubeus (XI'-XII siècles). Texte édité, traduit et annoté. Herausgegeben von Georges Pons und Jean Cabanot. Dax: Comité d'Études sur l'Histoire et l'Art de la Gascogne, 2004.

Cartulaire de Maguelone. Tl. I-II. Herausgegeben von Jean Rouquette und André Villemagne. Montpellier: Valat, i 9 I 4.

Cartulaires des Hospitaliers et des Templiers en Dauphiné. Herausgegeben von Ulysee J. Chevalier. Vienne: Savigné, I 875.

$9^{8}$ Le dossier de l'affaire des Templiers, hrsg. v. Georges Lizerand (Paris: Champion I 923 ), I 3.

99 Alain Demurger, Die Verfolgung der Templer. Chronik einer Vernichtung I307-I3I4 (München: Beck, 2017), 275-282. 
Cartulaires des Templiers de Douzens. Herausgegeben von Paul Gérard und Élisabeth Magnou. Collection des Documents inédites sur l'Histoire de la France 3. Paris: Bibliothèque Nationale, I 965 .

Cartulaire du prieuré de Saint-Gilles de l'hôpital de Saint-Jean de Jérusalem (II20-I2Io). Herausgegeben von Daniel Le Blévec und Alain Venturini. Paris: CNRS-Editions, I 997.

Cartulaire général de l'Ordre des Hospitaliers de S. Jean de Jérusalem (II0o-I3IO). Bd. I. II00-I200. Herausgegeben von Joseph Delaville Le Roulx. Paris: Ernest Leroux, I 894. Cartulaire général de l'Ordre des Hospitaliers de S. Jean de Jérusalem (II00-I3IO). Bd. II. I 200-I 260. Herausgegeben von Joseph Delaville Le Roulx. Paris: Ernest Leroux, I 897 .

Cartulaire général de l'Ordre des Hospitaliers de S. Jean de Jérusalem (IIoo-I3IO). Bd. III. I26I-I300. Herausgegeben von Joseph Delaville Le Roulx. Paris: Ernest Leroux, I 899. Cartulaire général de l'ordre du Temple I I Ig?-IIso. Recueil des chartes et des bulles relatives à l'ordre du Temple. Herausgegeben von Gustave A. M. d'Albon. Paris: Champion, I9I 3.

Corpus iuris canonici, Pars II, Decretalium collectiones. Decretales Gregorii P. IX., Liber sextus decratalium Bonifacii P. VIII., Clementis P. V. constitutiones, extravagantes tum viginti Ioannis P. XXII. tum communes, editio Lipsiensis secunda post Aemilii L. Richteri, instr. Aemilius Friedberg. Lipsiae: B. Tauchnitz, I 88 I (Nachdruck: Graz: Akademische Druck- u. Verlagsanstalt, I 959).

Dekrete der ökumenischen Konzilien. Bd. II. Konzilien des Mittelalters vom ersten Laterankonzil (II23) bis zum fünften Laterankonzil (ISI2-ISI7). Herausgegeben von Giuseppe Alberigo. Paderborn-München: Schöningh, 2000.

Gallia Christiana Novissima. Tl. I. Aix, Apt, Fréjus, Gap, Riez et Sisteron. Herausgegeben von Joseph H. Albanès und Ulysee Chevalier. Montbéliard: Hoffmann, I 899.

Gallia Christiana Novissima. Tl. VII. Avignon. Herausgegeben von Joseph H. Albanès und Ulysee Chevalier. Valence: Imprimerie Valentinoise, 1920.

L'histoire des grands prieurs et du grand-prieuré de St-Gilles. Herausgegeben von Jean Raybaud. Supplément aux Mémoires de l'Académie de Nîmes 26. Nîmes: Clavel \& Chastanier, I 904.

Papsturkunden für Templer und Johanniter. Archivberichte und Texte. Herausgegeben von Rudolf Hiestand. Vorarbeiten zum Oriens Pontificius I, Abhandlungen der Akademie der Wissenschaften in Göttingen, Philologisch-Historische Klasse, Dritte Folge 77. Göttingen: Vandenhoeck \& Ruprecht, 1972.

Papsturkunden für Templer und Johanniter. Neue Folge. Herausgegeben von Rudolf Hiestand. Vorarbeiten zum Oriens Pontificius II, Abhandlungen der Akademie der Wissenschaften in Göttingen, Philologisch-Historische Klasse, Dritte Folge I 35. Göttingen: Vandenhoeck \& Ruprecht, I 984.

Regesta Honorii Papae III iussu et munificentia Leonis XIII Pontificis Maximi ex Vaticanis archetypis. Herausgegeben von Pietro Pressutti. Rom: Loescher, i 888. 


\section{SECONDARY SOURCES:}

Ahlhaus, Josef. Geistliches Patronat und Inkorporation in der Diözese Hildesheim im Mittelalter. Freiburg/Breisgau: Waibel, 1927.

Avril, Joseph. "Sources et caractères du livre synodal de Raimond de Calmont d'Olt, évêque de Rodez ( I 289)." In L'église et le droit dans le Midi (XII $-X I V^{e}$ siècles), herausgegeben von Henri Gilles und Jean-Louis Biget, 2 I 5-248. Cahiers de Fanjeaux 29. Toulouse: Privat, I 994.

Avril, Joseph. "Mort et sépulture dans les statuts synodaux du Midi de la France." In La mort et l'au-delà en France méridionale (XII $-X I V^{e}$ siècles), herausgegeben von JeanLouis Biget, 343-364. Cahiers de Fanjeaux 33. Toulouse: Privat, I 998.

Bellomo, Elena. The Templar Order in North-West Italy (II42 - c. I330). The Medieval Mediterranean. Peoples, Economies and Cultures, 400-I 500 72. Leiden-Boston: Brill, 2008.

Beltjens, Alain. “Trois questions à propos de l'hospitalier Gérard." Bulletin de la Société de l'histoire et du patrimoine de l'Ordre de Malte I 9 (2007): 3-59; 20 (2008): 5-52.

Burgtorf, Jochen. "Die Ritterorden als Instanzen der Friedenssicherung?" In Jerusalem im Hoch-und Spätmittelalter. Konflikte und Konfliktbewältigung - Vorstellungen und Vergegenwärtigungen, herausgegeben von Dieter Bauer, Klaus Herbers und Nikolas Jaspert, I65-200. Campus Historische Studien 29. Frankfurt/Main-New York: Campus-Verlag, $200 \mathrm{I}$.

Carcenac, Antoine-Régis. Les Templiers du Larzac. La commanderie du Temple de Sainte-Eulalie de Larzac. Nîmes: Lacour, 1994.

Carraz, Damien. "Christi fideliter militantium in subsidio Terre Sancte. Les ordres militaires et la première maison d'Anjou ( I 246- I 342)." In As Ordens Militares e as Ordens de Cavalaria entre o Ocidente e o Oriente. Actas do V Encontro sobre Ordens Militares, herausgegeben von Isabel C. Fernandes, 549-582. Palmela: Camara Municipal, 2009.

Carraz, Damien. "Les ordres militaires et la paix dans le Midi au XII ${ }^{\mathrm{e}}$ siècle." Provence Historique 63, Nr. 252 (2013): 235-253.

Carraz, Damien. Lordre du Temple dans la basse vallée du Rhône (II24-I3I2). Ordres militaires, croisades et sociétés méridionales. Lyon: Presses Universitaires de Lyon, 2005.

Carraz, Damien. "Ordres militaires, croisades et sociétés méridionales. L’ordre du Temple dans la basse vallée du Rhône (I I 24-I 3 I 2).” Tl. III, Thèse de doctorat nouveau régime, Université Lyon II, 2003.

Carraz, Damien. "Pro servitio maiestatis nostre. Templiers et hospitaliers au service de la diplomatie de Charles Ier et Charles II." In La diplomatie dans les états angevins aux XIII et XIV siecles. Diplomacy in the Countries of the Angevin Dynasty in the thirteenth - fourteenth Centuries. Actes du colloque international de Szeged, Visegrád, Budapest, I3-I6 septembre 2007, herausgegeben von Zoltán Kordé und Istvan Petrovics, 2 I-4I. Rom-Szeged: Accademia d'Ungheria in Roma, 20 Io.

Carraz, Damien. "Sub eiusdem pacis et treugue Dei defensione. Die Ritterorden und der Friede in Südfrankreich im I 2. Jahrhundert." Ordines Militares Colloquia Torunensia Historica. Yearbook of the Study of the Military Order 17 (201 2): I 7-39. 
Carraz, Damien. “Templiers et Hospitaliers en France méridionale (XII"-XIII" siècles). À propos d'un ouvrage récent." Provence Historique 50, Nr. 200 (2000): 200-237.

Carraz, Damien. "Un revival de la paix de Dieu? Les paix diocésaines dans le Midi." In La reforme 'grégorienne’ dans le Midi, milieu XI $I^{e}$ début XIII' siècle, herausgegeben von Michelle Fournié, 523-558. Cahiers de Fanjeaux 48. Toulouse: Privat, 20 I 3.

Carraz, Damien und Yoan Mattalia. "Images et ornements. Pour une approche de l'environnement visuel des ordres militaires dans le Midi (XII ${ }^{\mathrm{e}}$-XIII ${ }^{\mathrm{e}}$ siècle)." In Images et ornements autour des ordres militaires au Moyen Age. Culture visuelle et culte des saints (France, Espagne du Nord, Italie), herausgegeben von Damien Carraz und Esther Dehoux, 47-68. Toulouse: Presses Universitaires du Midi, 2016.

Chiffoleau, Jacques. "Les transformations de l'économie parroisiale en Provence (XIII $-\mathrm{XV}^{\mathrm{e}}$ siècles)." In La parrocchia nel medio evo. Economia, scambi, solidarita, herausgegeben von Agostino Paravicini-Bagliani und Véronique Pasche, 6 I - I I 7. Italia Sacra. Studi et Documenti di Storia Ecclesiastica 53. Rom: Herder, I 995.

Chiffoleau, Jacques. "Sur l'économie paroissiale en Provence et en Comtat Venaissin du XIII ${ }^{\mathrm{e}}$ au XV $\mathrm{XV}^{\mathrm{e}}$ siècle." In La Paroisse en Languedoc (XIII ${ }^{e}-X I V^{e}$ siècles), herausgegeben von Marie-Humbert Vicaire, 84- I I 0 . Cahiers de Fanjeaux 25. Toulouse: Privat, 1990.

Delaruelle, Étienne. “Templiers et Hospitaliers en Languedoc pendant la Croisade des Albigeois." In Paix de Dieu et Guerre Sainte en Languedoc au I $3{ }^{e}$ siècle, 3 I 5-334. Cahiers de Fanjeaux 4. Toulouse: Privat, I 969.

Dondi, Christina. "Liturgies of the Military Religious Orders." In The Genius of the Roman Rite. Historical, theological and pastoral Perspectives on catholic Liturgy, herausgegeben von Uwe M. Lang, I 43- I 58. Chicago: Hillenbrand Books, 20 i .

Durbec, Joseph-Antoine. "Les Templiers dans les Alpes-Maritimes. Notice historique sur les maisons et possessions du Temple dans les diocèses de Antibes-Grasse, Nice, Vence et Glandève." In Templiers et Hospitaliers en Provence et dans les Alpes-Maritimes, herausgegeben von Joseph-Antoine Durbec, 209-289. Grenoble: Mercure Dauphinois, $200 \mathrm{I}$.

Durbec, Joseph-Antoine. "Monographie de Biot. Histoire et géographie humaine (Documentation inédite)." Annales de la Société scientifique et littéraire de Cannes et de l'arrondissement de Grasse N.S. 7 (1935): 1 39-235.

Forey, Alan. "A Hospitaller Consilium ( 1274 ) and the Explanations advanced by Military Orders from Problems confronting them in Holy Land in the later thirteenth Century." Ordines Militares Colloquia Torunensia Historica. Yearbook for the Study of the Military Orders I 6 (20 I I) (Die Ritterorden in Umbruchs-und Krisenzeiten / The Military Orders in Times of Change and Crisis): 7-17.

Forey, Alan. "The Military Orders and the War against Christians in the I 3 th century." English Historical Review I 04 ( 1989 ): I -24.

Fournié, Michelle, Fabrice Ryckebusch und Agnès Dubreil-Arcin. "Jean XXII et le remodelage de la carte ecclésiastique du Midi de la France. Une réforme discrète." Revue d'Histoire Ecclésiastique 98 (2003): 29-60. 
Götz, Werner. "Kirchenschutz, Rechtswahrung und Reform. Zu den Zielen und zum Wesen der frühen Gottesfriedensbewegung in Frankreich.” Francia I I (1983): I 94-240 .

Gouron, André. "Diffusion des consulats méridionaux et expansion du droit romain aux XII ${ }^{\mathrm{e}}$ et XIII ${ }^{\mathrm{e}}$ siècles." In La science du droit dans le Midi de la France au Moyen Âge, herausgegeben von André Gouron, Aufsatz I. 26-76. Collected Studies Series 196. London: Variorum Reprints, 1984.

Gouron, André. "Les étapes de la pénétration du droit romain au XII siècle dans l'ancienne Septimanie." Annales du Midi 69 (1957): 103- 20.

Guzzo, Christian. "The Hospitallers and Charles I of Anjou. Political and economic Relations between the Kingdom of Sicily and the Holy Land." In The Military Orders. Bd. V, Politics and Power, herausgegeben von Peter W. Edbury, I03-I I 2. Aldershot: Ashgate, 20 I 2.

Hageneder, Othmar. Die geistliche Gerichtsbarkeit in Ober-und Niederösterreich von den Anfängen bis zum Beginn des Is. Jahrhunderts. Forschungen zur Geschichte Oberösterreichs Iо. Graz: Böhlau, I 967.

Hébert, Michel. "Autour de la cavalcade: les relations entre le comte de Provence, les Hospitaliers et la commune de Manosque (XIII-XIV siècles)." In Vie privée et ordre public à la fin du Moyen Âge. Études sur Manosque, la Provence et le Piémont (I25o-I450), herausgegeben von Michel Hébert, I 4 I - I 58 . Aix-en-Provence: Université de Provence, 1987.

Helmholz, Richard H. Kanonisches Recht und europäische Rechtskultur. Mit einem Vorwort von Peter Landau. Tübingen: Mohr Siebeck, 2013.

Hiestand, Rudolf. “Templer- und Johanniterbistümer und -bischöfe im Heiligen Land." In Ritterorden und Kirche im Mittelalter, herausgegeben von Zenon Hubert Nowak, I 43-I 66. Ordines Militares. Colloquia Torunensia Historica IX. Toruń: Uniwersytet Mikołaja Kopernika, I 997.

Holtzmann, Robert. Französische Verfassungsgeschichte von der Mitte des neunten Jabrhunderts bis zur Revolution. München-Berlin: R. Oldenbourg, I 9 го (Nachdruck: Darmstadt: Wissenschaftliche Buchgesellschaft, I965).

Kéry, Lotte. Gottesfurcht und irdische Strafe. Der Beitrag des mittelalterlichen Kirchenrechts zur Entstehung des öffentlichen Strafrechts. Konflikt, Verbrechen und Sanktion in der Gesellschaft Alteuropas. Fallstudien ı. Köln-Weimar-Wien: Böhlau 2006.

Kéry, Lotte. "Klosterfreiheit und päpstliche Organisationsgewalt. Exemtion als Herrschaftsinstrument des Papsttums?" In Rom und die Regionen. Studien zur Homogenisierung der lateinischen Kirche im Hochmittelalter, herausgegeben von Jochen Johrendt und Harald Müller, 83-I 44. Abhandlungen der Akademie der Wissenschaften in Göttingen N.F. 19. Berlin-Boston: de Gruyter, 20 I 2.

Krämer, Thomas. Dämonen, Prälaten und gottlose Menschen. Konflikte und ibre Beilegung im Umfeld der geistlichen Ritterorden. Vita Regularis, Abhandlungen 64. Münster: Lit-Verlag, 20 I 5 . 
Le Blévec, Daniel. "Aux origines des Hospitaliers de Saint-Jean de Jérusalem: Gérard dit 'Tenque' et l'établissement de l'ordre dans le Midi." Annales du Midi 89, Nr. I 32 (I 977): I 37-I 5 I.

Legras, Anne-Marie und Jean-Loup Lemaitre. "Le pratique liturgique des Templiers et des Hospitaliers de Saint-Jean de Jérusalem." In L'écrit dans la société médiévale. Divers aspects de sa pratique du XIe au XV siècle. Textes en hommage à Lucie Fossier, herausgegeben von Caroline Bourlet und Anne Dufour, 77-I 37. Paris: CNRS éditions, I 99 I.

Morton, Nicholas. "Institutional Dependency upon secular and ecclesiastical Patrons and the Foundations of the Trial of the Templars." In The Debate on the Trial of the Templars (1307-1317), herausgegeben von Jochen Burgtorf, Paul Crawford und Helen Nicholson, 33-43. Farnham, Burlington: Ashgate, 20 I 0.

Müller, Harald. Päpstliche Delegationsgerichtsbarkeit in der Normandie (I2. und frühes I3. Jahrbundert). Tl. I. Studien und Dokumente zur Gallia Pontificia 4. Bonn: Bouvier 1997.

Müller, Harald. "Streitwert und Kosten in Prozessen vor dem päpstlichen Gericht - eine Skizze." Zeitschrift der Savigny-Stiftung für Rechtsgeschichte. Kanonistische Abteilung 87 (200I): I 38-I 64 .

Nicholson, Helen. "Nolite confidere in principibus. The Military Orders' Relations with the Rulers of Christendom." In Élites et ordres militaires au Moyen Âge. Rencontre autour d'Alain Demurger, herausgegeben von Philippe Josserand, Luis F. Oliveira und Damien Carraz, 26 I-276. Collection de la Casa de Velázquez i 45. Madrid: Casa de Velázquez, 20 i 5.

Nicholson, Helen. "Saints venerated in the Military Orders." In Selbstbild und Selbstverständnis der geistlichen Ritterorden, herausgegeben von Roman Czaja und Jürgen Sarnowsky, 9 I - I I 3. Ordines Militares. Colloquia Torunensia Historica XIII. Toruń: Uniwersytet Mikołaja Kopernika, 2005.

Planta, Peter C. von. Adel, Deutscher Orden und Königtum im Elsaß des I3. Jabrhunderts unter Berücksichtigung der Johanniter. Freiburger Beiträge zur mittelalterlichen Geschichte 8. Frankfurt/Main u. a.: Peter Lang, 1997.

Planta, Peter C. von. "Advocacy and 'defensio' - the Protection of the Houses of the Teutonic Order in the Region of the Upper Rhine during the thirteenth and fourteenth Centuries." In The Military Orders. Bd. 6.2, Culture and Conflict in Western and Northern Europe, herausgegeben von Jochen Schenk und Mike Carr, 193-202. London-New York: Routledge, 2017.

Riley-Smith, Jonathan. "The Origins of the Commandery in the Temple and the Hospital." In La Commanderie. Institutions des ordres militaires dans l'Occident médiéval. Actes du premier colloque international du Conservatoire Larzac Templier et Hospitalier, "La commanderie, institution des ordres militaires dans l'Occident médiéval", tenu à Sainte-Eulalie-de-Cernon (Aveyron), du I 3 au Is octobre 20oo), herausgegeben von Anthony Luttrell und Léon Pressouyre, 9-18. Mémoires de la Section d'Archéologie et d'Histoire de l'Art du CTHS I 4. Paris: CTHS, 2002. 
Saige, Gustave. "De l'ancienneté de l'Hôpital Saint-Jean de Jérusalem. Donations dans l'Albigeois antérieures à la première croisade." Bibliothèque de l'École des Chartes 5 (I 864): 552-560.

Salvadó, Sebastián. "Templar Liturgy and Devotion in the Crown of Aragon." In On the Margins of Crusading. The Military Orders, the Papacy and the Christian World, herausgegeben von Helen Nicholson, 3 I -44. Farnham: Ashgate, 20 I I.

Sarnowsky, Jürgen. "The Priests in the Military Orders. A comparative Approach on their Standing and Role." In On the Military Orders in medieval Europe. Structures and Perceptions, herausgegeben von Jürgen Sarnowsky, Aufsatz XVIII. I-I 4. Collected Studies Series CS 992. Farnham-Burlington: Variorum Reprints, 20 I I.

Sayers, Jane. "The Proprietary Church in England. A Note on Ex ore sedentis (X.5.33.1 7)." Zeitschrift der Savigny-Stiftung für Rechtsgeschichte. Kanonistische Abteilung 74 (I 988 ): 23 I-245.

Schenk, Jochen. Templar Families. Landowning Families and the Order of the Temple in France, C. II20-1307. Cambridge: Cambridge University Press, 20 I 2.

Schreiber, Georg. Kurie und Kloster im 12. Jahrbundert. Studien zur Privilegierung, Verfassung und besonders zum Eigenkirchenwesen der vorfranziskanischen Orden vornehmlich aufgrund der Privilegien von Paschalis II. bis auf Lucius III. (Iogg-II 8I). Stuttgart: Ferdinand Enke, i 9 I 0.

Selwood, Dominic. Knights of the Cloister. Templars and Hospitallers in Central-Southern Occitania c. I I0o - c. I300. Woodbridge: Boydell, I 999.

Vogel, Christian. Das Recht der Templer. Ausgewählte Aspekte des Templerrechts unter besonderer Berücksichtigung der Statutenhandschriften aus Paris, Rom, Baltimore und Barcelona. Vita Regularis, Abhandlungen 33. Münster: Lit-Verlag, 2007.

Voyer, Cécile. "La pensée visuelle des Templiers et des Hospitaliers de Saint-Jean de Jérusalem au XIII ${ }^{e}$ siècle. Réflexions à partir du décor de quelques édifices du royaume de France." Cabiers de Civilisation Médiévale 59 (2016): 47-7 I.

West, Charles. "Monks, Aristocrats, and Justice: Twelfth-Century Monastic Advocacy in a European Perspective." Speculum 92, Nr. 2 (2017): 372-404.

Wetzstein, Thomas. "Resecatis superfluis? Raymund von Peñafort und der Liber Extra." Zeitschrift der Savigny-Stiftung für Rechtsgeschichte. Kanonistische Abteilung 92 (2006): 355-391. 